
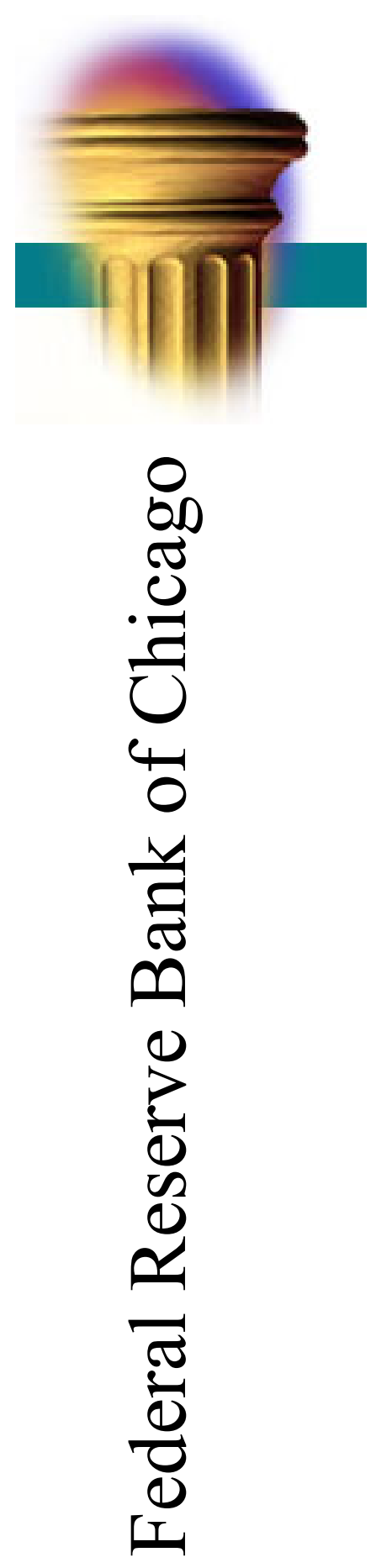

\title{
Delphic and Odyssean monetary policy shocks: Evidence from the euro area
}

Philippe Andrade and Filippo Ferroni

$$
\text { July 26, } 2018
$$

\section{WP 2018-12}

https://doi.org/10.21033/wp-2018-12

${ }^{*}$ Working papers are not edited, and all opinions and errors are the responsibility of the author(s). The views expressed do not necessarily reflect the views of the Federal Reserve Bank of Chicago or the Federal Reserve System. 


\title{
Delphic and Odyssean monetary policy shocks: Evidence from the euro area*
}

\author{
Philippe Andrade Filippo Ferroni \\ Banque de France Chicago FED
}

July 26, 2018

\begin{abstract}
We use financial intraday data to identify monetary policy surprises in the euro area. We find that monetary policy statements and press conferences after European Central Bank (ECB) Governing Council meetings convey information that moves the yield curve far out. Moreover, the nature of the information revealed in a narrow window around these statements and press conferences evolved over time. Until 2013, unexpected variations in future interest rates were positively correlated with the changes in market-based measure of inflation expectations consistent with news on future macroeconomic conditions. That negative correlation disappeared roughly when forward guidance on future rates started to be given by the Governing Council. We use conditions on the joint reaction of expected interest rates and inflation rates to disentangle the two types of monetary policy shocks (i.e. the Delphic and Odyssean monetary policy surprise). A surprise that lowers future interest rates does not engineer a boom. A surprise that lowers future interest rates because it signals future accommodation does.
\end{abstract}

Keywords: signaling, forward guidance, high frequency data, VAR with instrumented proxy, euro area

JEL Classification: C10, E52, E32.

\footnotetext{
${ }^{*}$ We would like to thank Benoit Mojon, Caroline Jardet, Julien Matheron, Francesco Ravazzolo, Aeimit Lakdawala, Jeff Campbell, Jonas Fisher, Alejandro Justiniano, Leonardo Melosi, Andrea Vedolin, Karel Mertens and Marco Del Negro, as well as the seminar participants at the Workshop on TVP models at the Bank of England, the JRC, the University of Lancaster, the Bank of Finland, the 2016 IAAE Conference, Chicago FED. We also are grateful with Refet Gurkaynak for his valuable comments. The views in this paper are solely the responsibility of the authors and should not be interpreted as reflecting the views of the Federal Reserve Bank of Chicago or any other person associated with the Federal Reserve System. The views expressed in this paper do not reflect those of Banque de France nor those of the Euro System.
} 


\section{INTRODUCTION}

The impact of monetary policy decisions on the yield curve is not limited to its short end: an interest rate hike today is often perceived as signaling future increases to come (see Gürkaynak, Sack and Swanson (2005b)). Because economic decisions depend on the whole path of expected interest rates, such evidence is viewed as proof that the information central banks reveal about future rates is an important channel through which monetary policy can impact the macroeconomy (see, e.g., Bernanke (2013)). Such evidence also gives support to the idea that monetary authorities can sustain aggregate demand by communicating that short-term interest rates will remain low for long when the policy rate can no longer be lowered because of the effective lower bound (ELB).

Yet, this view neglects the fact that two very different surprises can have an observationally equivalent impact on the yield curve. A drop in future rates can result from bad news on the future macroeconomic state to which the central bank will adjust following its reaction function. Alternatively, a drop in future rates can ensue from a commitment to future stimulative deviations from the normal time policy rule.

In this paper, we introduce a methodology to disentangle these two types of surprises and to assess their impact on financial and macroeconomic variables. We use the terminology introduced by Campbell, Evans, Fisher and Justiniano (2012) in their analysis of the US forward guidance policy and call the first type of surprise a "Delphic" shock as it corresponds to a situation where the central bank gives an oracle on the macroeconomic outlook. We call the second type of surprise an "Odyssean" shock as it corresponds to a situation where the central bank "ties its hands to the mast", promising to stick to the announced plan for the interest rate path and following through. We show that central banks' announcements can convey both Delphic and Odyssean information even when forward guidance policies are implemented. Finally, we provide evidence that only accommodative Odyssean surprises lead to a boom in aggregate activity.

More precisely, we use intraday data and assume that monetary policy shocks can be recovered from variations in interest rate swaps of up to a two-year maturity observed in a narrow window around monetary policy announcements as in Kuttner (2001) or Piazzesi (2002). Following Gürkaynak, Sack and Swanson (2005a), we decompose such variations into a component reflecting information about the current rate (the target factor) and a component reflecting information on future rates (the path factor). We apply this methodology to the euro area where monetary authorities announce policy decisions by a policy statement followed by a press conference at the end of every meeting of the Governing Council of the European Central Bank (ECB). We find that a positive shock to the path factor has a positive impact on the yield curve for horizons greater than two years. It also leads to an increase in expected inflation but has no impact on stock prices.

We then disentangle the Delphic and Odyssean components of monetary policy announce- 
ments, assuming different sign impacts on inflation expectations. In particular, we assume that an announcement about future monetary policy tightening has a Delphic nature if it raises the slope of the term structure of interest rates and generates a positive variation in inflation expectations (contemporaneously). When the opposite occurs, we define it as Odyssean. Since the latter generates an identified set, we consider the average impact to construct an observable proxy of the Odyssean shocks.

We find that our observable proxy of Odyssean monetary policy news shock displays desirable properties relative the path factor of Gürkaynak et al. (2005a). First, it is consistent with a narrative description of the latest episodes of the ECB monetary policy announcements. Second, it impacts daily financial instruments in accordance with our priors for the effect of an announcement about future monetary policy tightening (or accommodation). In particular, we find that an Odyssean announcement about monetary policy tightening moves the expected nominal interest rates up and inflation expectations down. Hence, by construction, expected real interest rates increase. While stock market prices do not react to the path factor, they decline in response to an Odyssean announcement about monetary policy tightening. Moreover, these responses display some form of persistence, and the impact of the Odyssean monetary policy announcement extends beyond the immediate business days following the monetary policy press conference.

We then offer a quantitative estimate of the dynamic propagation of Odyssean shocks on output and prices (measured by the industrial production index and by the Harmonized Index of Consumer Prices (HICP) excluding food and energy, respectively) and on survey expectations (according to Consensus Economics) on output growth and inflation and compare it with the one implied by the path factor. We identify the transmission mechanism by instrumenting the reduced-form VAR residuals with our observable measures of Odyssean monetary policy shocks as in Mertens and Ravn (2013) and Stock and Watson (2012). Our findings are as follows. A "generic" announcement of future rates hikes (i.e., an increase in the path factor) generates a boom in expectations about inflation and output growth prospects and an increase in prices. The latter result is difficult to rationalize as a standard transmission mechanism of an announcement about future monetary policy tightening unless we acknowledge a strong signaling effect of monetary policy. The dynamic transmission of the Odyssean shock does not lead to this interpretation: in response to an announcement about a future monetary policy tightening, we find that both actual prices and quantities, as well as expectations about them, decline.

The paper is organized as follows. In section 2, we present the data on market-based expectations of interest rates and of inflation rates. In section 3, we explain the identification strategy. In section 4 we estimate the Odyssean monetary policy surprises' dynamic impact on macroeconomic aggregates. Finally, we summarize our conclusion in section 5 . 


\subsection{Related Literature}

Gürkaynak et al. (2005a) show that Federal Open Market Committee (FOMC) announcements have strong effects on asset prices and, in particular, expected future policy rates, and Jardet and Monks (2014) offer similar evidence for monetary policy announcements made in the euro area. Romer and Romer (2000) provide evidence that FOMC decisions convey Fedspecific information about the macroeconomic outlook so that private agents update their forecasts accordingly. Using intraday data, Nakamura and Steinsson (2017) also emphasize such signaling effect using intraday data but do not identify the two types of shocks (Delphic and Odyssean). Campbell et al. (2012) confirm such results in a sample that includes the Great Recession. Their results are consistent with market participants interpreting FOMC's announcements as being Delphic rather than Odyssean. For the euro area, we show that the two interpretations of announcements about future monetary policy stance coexisted. Besides the fact that it is important to understand if these announcements made private agents more optimistic or pessimistic about the future, the existence of these two types of shocks creates an identification problem for those studies that analyze how economic and financial variables respond to shifts in monetary-policy expectations without making this distinction (e.g. Gertler and Karadi (2015)).

However, teasing these two shocks apart is difficult. Campbell, Fisher, Justiniano and Melosi (2017) use the difference between the Blue Chip forecasts and the Greenbook forecasts as an observable proxy for information asymmetry. They interpret the latter as the amount of Delphic forward guidance contained in the monetary policy announcements for the US experience. Similarly, Miranda-Agrippino (2015) propose to extract dynamic factors from a dataset including public and central bank (Greenbook forecasts) information set and to remove the predictability of the factors from the variation of rates in a narrow window of the monetary policy announcements. We argue that for the euro area experience we lack appropriate measures of information asymmetry and, hence, these approaches are not suitable. D'Amico and King (2015) consider a VAR with slowly moving (quarterly) variables and survey data on expectations on interest rate, inflation, and output. To identify Odyssean and Delphic shocks, they impose different sign restrictions on the pattern of the expected shortterm rate on the one hand and the expected inflation and expected GDP on the other. This identification strategy is attractive because it isolates shocks in which Odyssean guidance dominates Delphic guidance. Our approach is similar; we impose zero and sign restrictions to isolate these shocks. The main difference is on the frequency of the observations. While they consider slowly moving variables, we focus on variations of interest and inflation rate expectations in a narrow window around the monetary policy announcement. The paper most closely related to our approach is Karadi and Jarocinsky (2018), where they combine low- and high-frequency variables in a VAR and study the transmission of monetary policy in the US and in the euro area. Similarly to what we do, they introduce sign and zero re- 
strictions to identify what they call monetary policy (Odyssean) and information (Delphic) surprises. In contrast to what we do, they impose opposite sign restrictions on interest rate and stock market price variations. While an interest rate hike accompanied by declines in stock market prices is interpreted as an Odyssean monetary policy surprise, the interest rate hike can be the result of the endogenous response to a supply side information shock. Imposing sign restrictions on market-based inflation expectations does not lead to this ambiguity. Moreover, while Karadi and Jarocinsky (2018) focus on unexpected monetary policy shocks, we study the effects of forward guidance or, in general, announcements about future monetary policy. Miranda-Agrippino and Ricco (2017) propose to remove the predictable component of the US high-frequency interest rate variations from the Greenbook's forecasts and forecast revisions and use the residual as a proxy for the monetary policy shock. For the euro area, we do not find evidence that announcements about future monetary policy respond to ECB and Eurosystem staff macroeconomic projections and forecast revisions.

An alternative avenue is to consider a structural model (e.g., a DSGE model) and study the transmission of the monetary policy announcements (or news) of the estimated version of the model. However, several authors have expressed concerns that quantitatively standard DSGE models predict incredibly high positive impacts of forward guidance policies on future inflation and activity; see, e.g., Carlstrom, Fuerst and Paustian (2015) and Del Negro, Giannoni and Patterson (2012). Bringing discounting to the linearized inter-temporal consumption Euler equation reduces the impact of these policies, as discussed by Kiley (2016) and McKay, Nakamura and Steinsson (2015). Moreover, information imperfections and heterogeneous beliefs can generate macroeconomic outcomes that are opposite to the ones of the standard full information rational expectation benchmark. However, the quantitative assessments depend crucially on the model specification. In this paper, we impose only a minimal amount of theory, which is based on the sign of co-movement between the slope of the term structure of nominal interest rates and the inflation expectations.

\section{Market-Based Expectations of Interest Rates AND Inflation}

In this section, we assess empirically the ability of the ECB to communicate future policy intentions to the private sector. By using high-frequency data on market interest rates, we measure the changes in interest rate futures associated with ECB statements from January 2002 until January 2016. The construction of interest rate variations follows closely the work about the euro area of Jardet and Monks (2014), who have drawn insights from the analysis about the US experience of Gürkaynak et al. (2005a). ${ }^{1}$ The key idea is to isolate the variations in the current and future market interest rates at different maturities (up to two years) in a narrow window around the monetary policy decision and press conference. We estimate two factors that explain most of these variations: a target (intercept) factor that moves the current and expected policy rates and a path (slope) factor that only moves

\footnotetext{
${ }^{1}$ In Jardet and Monks (2014) the sample spans from 2002 until 2013. Here we extend the sample until $2016 \mathrm{~m} 1$.
} 
expected future rates. We then measure their impact on market-based inflation expectations and stock market prices. Various results emerge, all pointing to substantial instability in the impact of the path factor on market based inflation expectations and stock price variations over time. In particular, we find that in central portion of our sample an unanticipated increase in the path factor triggered an upward revision in the forecast of inflation. Toward the end of our sample, we find that most of these impacts change signs and the monetary policy announcements had an Odyssean component, meaning that a decline in the expected rates triggered an increase in market-based inflation expectations.

\subsection{The IMPACT of THE ECB ANnOUnCEMENTS ON INTEREst RATES}

We consider the changes in the forward overnight index swaps (OIS) ${ }^{2}$ in a 30-minute window around the ECB's monthly interest rate announcements and conference press from January 2002 until January 2016. Forward OIS rates are commonly used to measure expectations of the future path of the euro overnight index average (EONIA) and by having as a counterpart payment only the accrued interest rate payments, they are less sensitive to fluctuations in the credit risk premia. The data are extracted from the Thomson Reuters Tick History application. The database consists of minute by minute mid-quote rates for OIS contracts of different maturities up to two years during the days of the ECB monetary policy announcements. We consider eight maturities from the current month until two years ahead. ${ }^{3}$ We calculate the difference of each OIS forward rate using five-minute averages before the start and after the end of a window around the ECB interest rate announcement and press conference. In particular, the ECB interest rate announcement and monetary policy decision is posted on the ECB webpage at 13:45 and the press conference begins around 14:30 and lasts one hour. The conference usually starts with the ECB President's reading of the introductory statement which contains the motivation of the monetary policy decisions and is followed by a questions-and-answers $(\mathrm{Q} \& \mathrm{~A})$ part. The length of the introductory statement is approximately 10/15 minutes and the rest of the time is allocated for the questions of the journalists and participants. We thus define the identification window as beginning at 13:35 and ending at 15:50.

Figure 1 reports the fluctuations in the one-month and the one-year OIS rates on the day of the ECB monetary policy decision and press conference in July 2013 and in January 2015.

These dates are selected because they are associated with key decisions taken by the ECB

\footnotetext{
${ }^{2}$ The overnight index swap (OIS) is an interest rate swap where the periodic floating payment is generally based on a return calculated from a daily compounded interest investment. The reference for a daily compounded rate is an overnight rate (or overnight index rate) and for the euro area is the EONIA rate.

${ }^{3}$ For each maturity, mid-quotes figures are transformed into forwards using the following formula

$$
r_{t_{1}, t_{2}}=\left(\frac{\left(1+r_{2}\right)^{d_{2}}}{\left(1+r_{1}\right)^{d_{1}}}\right)^{\frac{1}{d_{2}-d_{1}}}-1
$$

where $t_{1}$ refers to the start of the forward rate, $t_{2}$ to the end of the forward rate, and $d 1$ and $d_{2}$ to the respective day counts.
} 


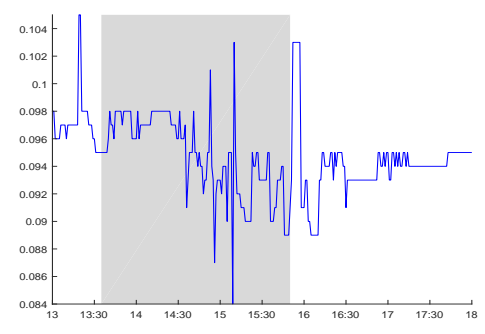

(a) July 2013: OIS 1M



(d) January 2015: OIS 1M

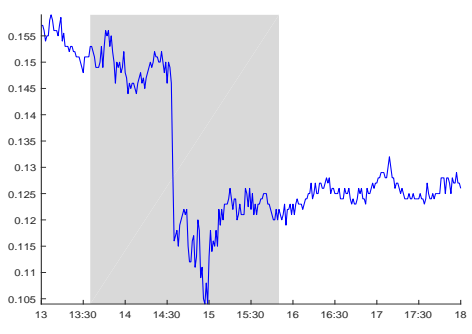

(b) OIS $1 Y$

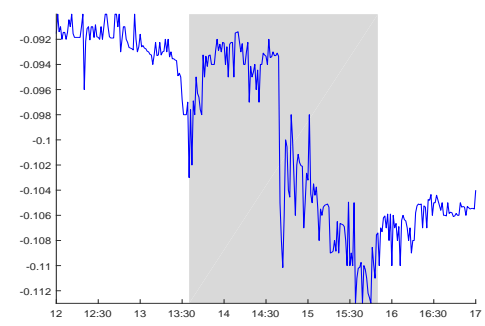

(e) OIS $1 Y$



(c) STOXXE

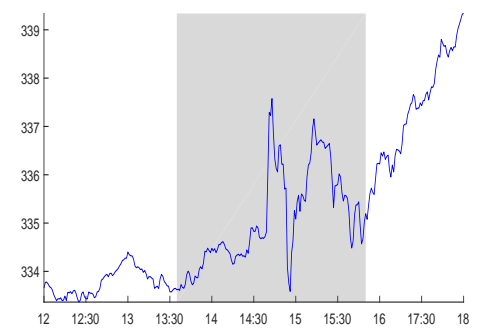

(f) STOXXE

Figure 1: One-month (left) and one-year (center) OIS fluctuations, and Euro STOXX index on day of the ECB press conference. Top panels report the July 2013 press conference day where forward guidance about the key ECB interest rate to stay at present or lower levels for an extended period of time is announced. The bottom panel corresponds to the announcement about the full blown quantitative easing (QE) package. Gray shaded areas report the identification window.

Governing Council. During the July 2013 press conference, President Draghi announced for the first time forward guidance; the introductory statement of that press conference states: "[The GC] expects the key ECB interest rate to remain at present or lower levels for an extended period of time." At 13:45 on the 22nd of January of 2015 the Governing Council announced the intention to implement further monetary monetary measures, and at 14:30 Presisdent Draghi described the ECB's intention to expand the Asset Purchases Program to government bonds, with details on the duration and on the amount of assets to be bought. In both events, the market reacted sharply.

The short-term rate (1M OIS) did not display any particular pattern and looked pretty erratic. Given the binding lower bound since 2012, this is not surprising. The one-year OIS rate does present interesting variations. In July 2013, the Governing Council did not change the monetary policy stance, i.e., the monetary policy decision was to keep the monetary stance unchanged. However, during the introductory statement at the beginning of the press conference at 14:30, the long-term interest rate felt significantly, i.e., from 15 basis points to 10. On the 22nd of January 2015, we can notice a series of declines in the one-year OIS, i.e., two sharp declines at 13:45 and at the beginning of the press conference and a steady and gradual one during the Q\&A part. This seems to suggest that not only the announcement about the quantitative easing (QE) moved markets prices and expectations but also the motivations behind this choice. 
From the term structure of variations in forward OIS rates, we extract the first two principal components that explain the largest portion of variation in the standardized data set. The identification of the factors is performed by rotating the factors in such a way that the second factor (path) explains the variation in all OIS futures contracts but the current-month interest rate variation. ${ }^{4}$ Both estimated and rotated factors have zero mean and zero autocorrelation and partial autocorrelation functions, and by construction they are orthogonal to each other (see figure 7). The target factor is usually interpreted as a conventional monetary policy surprise, and the path factor as a forward guidance shock or as a large asset purchases shock that affects the slope of the term structure of the interest rates (i.e., the correlation between the path factor and the spread between the one-year and one-month OIS rates is 0.94, see Figure 8).

\begin{tabular}{|c|c|c|c|c|c|c|}
\hline \multirow[b]{2}{*}{ OIS futures } & \multicolumn{6}{|c|}{ Variance Decomposition } \\
\hline & $\begin{array}{l}2002 \mathrm{~m} 1 \\
\text { Target }\end{array}$ & $\begin{array}{c}016 \mathrm{~m} 1 . \\
\text { Path }\end{array}$ & $\begin{array}{l}2002 \mathrm{~m} \\
\text { Target }\end{array}$ & $\begin{array}{l}11 \mathrm{~m} 12 \\
\text { Path }\end{array}$ & $\begin{array}{l}2012 \mathrm{~m} \\
\text { Target }\end{array}$ & $\begin{array}{c}016 \mathrm{~m} 1 . \\
\text { Path }\end{array}$ \\
\hline Current month (0-30) & 85 & 0 & 84 & 0 & 93 & 0 \\
\hline Next month $(30-30)$ & 66 & 17 & 66 & 17 & 67 & 19 \\
\hline Next Quarter (90-90) & 42 & 49 & 44 & 49 & 27 & 59 \\
\hline Two Quarter hence (180-90) & 25 & 67 & 26 & 67 & 15 & 73 \\
\hline Three Quarter hence (270-90) & 16 & 76 & 16 & 76 & 7 & 83 \\
\hline One year hence $(360-90)$ & 15 & 78 & 15 & 78 & 9 & 81 \\
\hline Five quarter hence (450-90) & 8 & 80 & 8 & 79 & 5 & 88 \\
\hline One year and half hence (540-90) & 11 & 57 & 12 & 55 & 7 & 75 \\
\hline Seven quarter hence $630-90$ & 2 & 64 & 2 & 62 & 0 & 84 \\
\hline
\end{tabular}

Table 1: Decomposition of the variance in changes in OIS futures, full sample and subsamples, i.e., $2002 \mathrm{~m} 1-2011 \mathrm{~m} 12$ and 2012m1-2016m1.

One interesting exercise is to assess the relative contribution of each identified factor in explaining the volatility of the OIS futures at various maturities. The first two columns of table 1 report the fractions of variance of each interest rate futures contract rate that are due to the identified target factor and to the identified path factor over the sample period of January 2002 until January 2016. The variance is computed as the $R^{2}$ of the regression of each futures contract on the target or path factor. The path factor accounts for no changes in the current-month interest rate, and it accounts for only $17 \%$ of the variance in the interest rate expected for the next month. The target factor accounts for nearly all of the remaining variance from these two contracts. The path factor and the target factor each explain about $40-50 \%$ of the variance in interest rates expected for the next quarter. Finally, the path factor dominates in explaining the volatility of OIS futures contract expected at maturities

\footnotetext{
${ }^{4}$ We normalize the target factor loadings on the current OIS rates and the path factor loading on the one-yearahead future to unity. Gürkaynak et al. (2005a) and Jardet and Monks (2014) use a slightly different normalization. This normalization has no impact on the variance decomposition and statistical significance.
} 
longer two quarters. The remaining columns of table 1 carry the same information using two different subsample periods. In particular, we consider the ECB announcements from January 2002 until January 2012 and from then until January 2016. The two subsamples are chosen because characterized by very different economic conditions. The large swings in oil prices preceding the Great Recession, the global financial turmoil of 2009, the euro area sovereign debt crisis, and the short-term rates hitting the effective lower bound and a novel set of unconventional monetary policy tools implemented by the ECB in response. Moreover, one could argue that the communication strategy of the ECB has adapted to this dramatically changing environment, moving from a "no pre-commitment" attitude as it was the case during the Trichet presidency toward more forward-looking statements and commitments. All this is reflected in column 4 and 6 of table 1 where the portion of variance explained by the path factor for OIS future contracts at long horizons is larger during 2012 to present. For example, the path factor explains $55 \%$ of the volatility the one year and half ahead OIS future contracts during Trichet tenure (2003-2011) and 78\% thereafter.

While explaining a large portion of volatility in intraday OIS futures, one may wonder how much these surprises contribute to the variation of interest rates at lower frequencies - say, monthly variations. Table 2 shows the regression of the monthly variations in (spot) EONIA swaps at various maturities on target and path factors (and a constant, though the results are not shown).

$$
\Delta^{\text {monthly }} O I S_{t}=\alpha_{0}+\alpha_{1} f_{t}^{\text {target }}+\alpha_{2} f_{t}^{\text {path }}+e_{t}
$$

The path factor loads significantly in the monthly variation of (spot) EONIA swaps at various maturities. The share of variance of monthly variations in EONIA swaps explained by the two factors is between $10 \%$ and $20 \%$ for one-year to three-years maturities for the full sample. This share increases up to around $40 \%$ in the second part of the sample. Similar patterns can be found for the average euro area government bond rates and Euribor interest rates.

\subsection{The PREDictability of ECB MONETARY POLICY}

Before treating these observed measures as proxiees for the exogenous shifts in the current and future stance of monetary policy, it is important to assess if they are indeed exogenous and cannot be predicted using the information set available before the conference. In other words, can the variations in the target and path factors be explained by the data of the month before the press conference? If so, then the monetary policy shocks we are trying to measure cannot be treated as "surprises" or exogenous.

One simple way to test the predictability is to project the the path and target factors onto a set of variables intended to capture the information set common to the central bank and the agents. Let $\eta_{t}$ be the vector containing the target and path factors at time $t$ and let $X_{t}$ a vector collecting a number of macroeconomic and financial variables. We define the 
Sample 2002-2016

Sample 2002-2012

Sample 2012-2016

\begin{tabular}{c|ccccccccc} 
& \multicolumn{4}{|c}{ Sample 2002-2016 } & \multicolumn{3}{c}{ Sample 2002-2012 } & \multicolumn{3}{c}{ Sample 2012-2016 } \\
Eonia Maturity & Target & Path & Adj $R^{2}$ & Target & Path & Adj $R^{2}$ & Target & Path & Adj $R^{2}$ \\
\hline & & & & & & & & & \\
One month & 0.44 & 0.31 & 0.01 & 0.27 & 0.34 & 0.00 & $1.40^{* * *}$ & 0.09 & 0.43 \\
Three months & 0.34 & $0.48^{* *}$ & 0.02 & 0.19 & $0.49^{*}$ & 0.01 & $1.28^{* * *}$ & $0.39^{* * *}$ & 0.41 \\
Six months & 0.36 & $0.75^{* * *}$ & 0.06 & 0.20 & $0.77^{* * *}$ & 0.05 & $1.33^{* * *}$ & $0.65^{* * *}$ & 0.43 \\
One year & 0.42 & $1.17^{* * *}$ & 0.11 & 0.27 & $1.20^{* * *}$ & 0.10 & $1.28^{* * *}$ & $1.02^{* * *}$ & 0.43 \\
Two years & 0.62 & $1.48^{* * *}$ & 0.15 & 0.46 & $1.49^{* * *}$ & 0.14 & $1.63^{* * *}$ & $1.49^{* * *}$ & 0.41 \\
Three years & -0.18 & $1.69^{* * *}$ & 0.21 & -0.55 & $1.72^{* * *}$ & 0.20 & $1.70^{* *}$ & $1.85^{* * *}$ & 0.34 \\
Five years & -0.44 & $1.44^{* * *}$ & 0.16 & -0.91 & $1.40^{* * *}$ & 0.16 & $2.08^{*}$ & $2.14^{* * *}$ & 0.27 \\
Ten years & $-1.09^{*}$ & $0.92^{* * *}$ & 0.07 & $-1.33^{*}$ & $0.95^{* * *}$ & 0.10 & 0.15 & 1.08 & 0.00 \\
\hline & & & & & & & & &
\end{tabular}

Table 2: Regression estimating the monthly variation of EONIA swaps at the different maturities explained by the (intraday) target factor and the path factor. One (two, three) star indicates the statistical significance at $1 \%(5 \%, 10 \%)$ computed with robust standard errors.

following system

$$
\begin{aligned}
X_{t} & =\Lambda \mathbf{f}_{t}+u_{t}, \\
\eta_{t+1} & =\mathbf{f}_{t}^{\prime} B+e_{t+1},
\end{aligned}
$$

where $e_{t}$ and $u_{t}$ are independent identically distributed (i.i.d.) shocks, and $B$ is the matrix that loads the factors onto the monetary policy surprises. If $B$ is statistically significant, then monetary policy surprises can be predicted by using past common information.

The test is run in various steps. We first extract the first principal components that explains about 70 percent of the volatility of the entire data set. Factors are extracted on a rolling basis in order to avoid including the information available after the announcement. In a second step, we regress the path and target factors on the lagged factors and look at the $F$ and $t$ statistics to test for statistical significance. Note that $X_{t}$ contains the set of observables whose realizations are known before the announcement. About 40 variables are considered, including macro data, financial variables, and surveys results. ${ }^{5}$

Table 3 reports the individual p-values of the coefficients of the regression of the path and target factors on lagged macroeconomic, financial and surveys factors or only lagged financial factors. The last row reports the the $\mathrm{F}$ test of the joint statistical significance. Overall, the publicly available information seems to explain very little of the interest rate variations in a narrow window around the monetary policy press conference. If anything, one macro factor appears to be statistical influential in explaining the target factor. ${ }^{6}$ However, monetary policy announcements about future monetary policy actions (path factor) are not

\footnotetext{
${ }^{5}$ The selection of variables is pretty standard for the euro area and mimics the choices in Banbura and Modugno (2014). More details on selection and transformation of variables is reported in the appendix; see table 10.

${ }^{6}$ Factor 5 can be associated with measures of inflation. Table 17 in the appendix reports the regression estimating $f_{5}$ on each observable variable in the factor model, $f_{5, t}=\alpha_{0}+\alpha_{0} X_{j, t}+e_{t}$. Individual regressions are ranked with respect to the $R^{2}$. Core and headline HICP inflation explain one-fourth of the variation in the $f_{5, t}$.
} 


\begin{tabular}{c|cccc} 
& \multicolumn{5}{|c}{ P-values } \\
& \multicolumn{3}{|c}{ Full data set } & \multicolumn{2}{c}{ Only Financial } \\
& Target & Path & Target & Path \\
\hline & & & & \\
$c$ & 0.39 & 0.36 & 0.31 & 0.40 \\
$f_{1}$ & 0.28 & 0.40 & 0.37 & 0.40 \\
$f_{2}$ & 0.14 & 0.34 & 0.18 & 0.27 \\
$f_{3}$ & 0.09 & 0.39 & 0.24 & 0.37 \\
$f_{4}$ & 0.30 & 0.39 & 0.35 & 0.39 \\
$f_{5}$ & 0.02 & 0.29 & & \\
$f_{6}$ & 0.27 & 0.38 & & \\
$f_{7}$ & 0.22 & 0.21 & & \\
$f_{8}$ & 0.39 & 0.31 & & \\
& & & & \\
F test & 1.498 & 0.393 & 0.850 & 0.250 \\
& & & & \\
\hline & & & &
\end{tabular}

Table 3: Predictability of monetary policy announcements. P-values of the regression of the paths and target factors on macroeconomic and financial lagged factors. Last row reports the F statistics.

predictable using past information. ${ }^{7}$

While factors are not predictable using the information available to the private sector and to the central bank, Campbell et al. (2017) raised the concern that the private sector's and the central bank's information sets might not be the same before the conference press and constructed a measure of information discrepancy. Unfortunately, for the euro area we lack a sensible measure of asymmetry, and the empirical measures of in the private sector's and central bank's expectations are little informative for the scopes of this paper (see Appendix A.3).

\subsection{The IMPACT OF ECB ANNOUNCEMENTS ON INFLATION EXPECTATIONS}

Has the ECB forward guidance made market participants more optimistic or pessimistic? To answer this question, we gather the daily figures on inflation-linked swaps (ILS) at various maturities as proxies for market-based inflation expectations. Inflation-linked swaps are an outstanding source of information about private sector inflation expectations, particularly for short-term horizons. An ILS is a contract that involves an exchange of a fixed payment (the so-called "fixed leg" of the swap) for realized inflation over a predetermined horizon. Thus, through the construction of the contract, the fixed swap rate provides a direct reading of the market's expected inflation rate. They are available daily over a wide range of horizons. An alternative financial market indicator is the break-even inflation rate, which is calculated as the yield spread between nominal and inflation-linked bonds. In contrast, inflation-linked

\footnotetext{
${ }^{7}$ If interested in studying the properties of the target factor, one could take the residuals of the regression of the target factor on $f_{5}$ and treat them as a measure of a monetary policy surprise; see, e.g., Miranda-Agrippino (2015).
} 
ILS 2Y ILS 5Y ILS 10Y ILS 15Y STOXX

\begin{tabular}{ccccccc} 
& & ILS 2Y & ILS 5Y & ILS 10Y & ILS 15Y & STOXX \\
\hline \multirow{2}{*}{$2002-2016$} & Target & $-0.41^{*}$ & -0.08 & 0.12 & 0.05 & $-5.06^{* *}$ \\
& Path & $0.34^{* * *}$ & $0.24^{* * *}$ & $0.17^{* * *}$ & $0.13^{* *}$ & -0.19 \\
& Adj $R^{2}$ & 0.07 & 0.09 & 0.06 & 0.04 & 0.02 \\
& & & & & & \\
$2002-2012$ & Target & -0.37 & -0.02 & 0.18 & 0.11 & $-7.19^{* * *}$ \\
& Path & $0.38^{* * *}$ & $0.28^{* * *}$ & $0.20^{* * *}$ & $0.17^{* * *}$ & 0.23 \\
& Adj $R^{2}$ & 0.09 & 0.14 & 0.12 & 0.09 & 0.08 \\
& & & & & & \\
$2012-2016$ & Target & -0.64 & $-0.73^{* *}$ & $-0.83^{* * *}$ & $-0.58^{* *}$ & -2.47 \\
& Path & $-0.64^{* * *}$ & $-0.69^{* * *}$ & $-0.63^{* * *}$ & $-0.81^{* * *}$ & -1.42 \\
& Adj $R^{2}$ & 0.24 & 0.27 & 0.51 & 0.55 & -0.01 \\
& & & & & & \\
\hline
\end{tabular}

Table 4: Regression estimating responses of the revision of ILS to target and path factors, full sample and subsamples. The target (path) factor is normalized so that it generates a $1 \%$ increase in the 1 month (year) OIS futures. One, two, and three asterisks indicate statistical significance at $10 \%, 5 \%$, and $1 \%$, respectively.

swaps: (i) do not require the estimation of nominal and real term structures, thereby avoiding problems related to the limited number of bonds at short maturities; (ii) are less prone to liquidity distortions resulting from turbulence in financial markets than break-even inflation rates; (iii) are less affected by HICP seasonality than than break-even inflation rates, and are therefore more suitable for monitoring inflation expectations at short horizons. ILS, as with all market-based indicators of inflation expectations, may include an inflation risk premium component to compensate investors for the risks surrounding inflation expectations over the forecast horizon. Available euro area evidence suggests that such a premium increases with maturity length, but remains very limited in size and variability at the horizons considered (see Garcia and Werner (2010)). In the specific case of the euro area, the ILS market has grown rapidly since 2003, reflecting the increasing demand for inflation-linked instruments and the relatively limited supply of index-linked bonds.

In particular, we run the following regression

$$
\Delta I L S_{t+1, t-1}=\alpha_{0}+\alpha_{1} \eta_{t}^{\text {target }}+\alpha_{2} \eta_{t}^{\text {path }}+u_{t}
$$

where $\eta^{j}$ denotes the monetary policy surprise for $j=$ target, path. Table 4 reports the coefficient estimates for $\alpha_{1}$ and $\alpha_{2}$ and the adjusted $R^{2}$ for the full sample and for different subsamples. ${ }^{8}$ The target (path) factor is normalized so that it generates a $1 \%$ increase in the 1 month (year) OIS futures. The last column of table 4 reports the impact of the path and target factors on the (intraday) variation in the Euro Stoxx 50 during the ECB press

\footnotetext{
${ }^{8}$ Tables 13-16 in the appendix reports the regression of the 1 day or 2 days variations in (Spot and Forwards) ILS on target and path factors. We considered as baseline the 2 days variations because the adjusted $R^{2}$ is larger. However, the signs on the coefficients are qualitative similar to the exact specification used, i.e. using forward or spot rates within a one- or two-day variation.
} 
conference. A number of interesting results are worth highlighting. First, when significant, coefficients loading the target factor have negative signs, meaning that an increase in the target factor generates a decline in the inflation expectations, which is consistent with the announcement of a monetary policy tightening. Second, the path factor which captures the announcements about future monetary policy is significant and positive at any horizon. Third, the path factor has a positive impact during the first subsample period and a negative impact during the second one. This indicates that, while for the first subsample the ECB announcements are characterized by a strong Delphic attitude, our estimates for the second subsample suggests a vanishing importance of the Delphic component. More precisely, our estimates indicate that since January 2012 the ECB announcements generating a 1 percent reduction in the one-year OIS futures rate were able to generate an increase of roughly 30 basis points in inflation swaps at the two-years horizon. Similarly, the impact of the path factor on stock market prices has been relatively unstable in the two subsamples. These time variations in the response of inflation expectations are still visible when we use rolling estimates or local kernel estimators instead of considering arbitrary subsamples (see A.4).

\section{Identifying the Delphic and Odyssean components of ECB ANNOUNCEMENTS}

The results of the previous sections highlight the fact that the path factor (i.e. variations in the slope of the term structure of the interest rates) had varying impact on the euro area inflation expectations. Standard macroeconomic models have something to say about the co-movements between the slope of interest rates and expected inflation conditional on monetary policy news. And we can use these insights to discipline the properties of monetary policy announcements. We take as an example of the transmission mechanism of monetary policy announcements the one present in the textbook three-equations New Keynesian (NK) model, as presented in Woodford (2003) or in Nakamura and Steinsson (2013). The first equation of the NK model is the investment/saving (IS) curve (derived from linearizing the Euler equation), which relates the current output gap with the expected output gap and the gap between the real rate and the natural interest rate, i.e.,

$$
x_{t}=x_{t+1, t}-1 / \sigma\left(i_{t}-\pi_{t+1, t}-r_{t}^{n}\right),
$$

where $x_{t}$ is the output gap, $x_{t+1, t}$ is the expected output gap, and $r_{t}^{n}$ is the real interest rate, i.e., the rate that would prevail if prices were fully flexible. Solving forward, we obtain an expression where the output gap is the sum of future deviation of the real interest rate from the natural rate of interest, i.e.,

$$
x_{t}=-1 / \sigma \sum_{j=0}^{\infty}\left(i_{t+j, t}-\pi_{t+1+j, t}-r_{t+j, t}^{n}\right) .
$$


The second equation of the NK model is the Phillips Curve, linking current inflation with the future expected inflation and the output gap, i.e.

$$
\pi_{t}=\beta \pi_{t+1, t}+\kappa x_{t}
$$

where $\pi_{t}$ and $\pi_{t+1, t}$ are current and expected inflation rates. Solving this equation forward, we obtain that current inflation can be expressed as the discounted sum of current and expected output gaps, i.e.,

$$
\pi_{t}=\kappa \sum_{j=0}^{\infty} \beta^{j} x_{t+j, t} .
$$

We assume that the central bank follows a very simple rule such that the real interest rate tracks the natural real rate with some error:

$$
r_{t}=i_{t}-\pi_{t+1, t}=r_{t}^{n}+e_{t, t-j}
$$

Absent any monetary shocks, the real interest rate will perfectly track the natural real rate and both the output gap and inflation will be zero.

A monetary policy announcement at time $t$ of, say, a monetary policy accommodation at time $t+N$ takes the form of a future decline in the real interest rate; i.e., the real interest rate will be lower for a single quarter $N$ quarters in the future, but maintained at $r_{t}^{n}$ elsewhere. That is,

$$
e_{t+N, t}<0 \rightarrow r_{t+N, t+N}-r_{t+N, t+N}^{n}<0 .
$$

Given the IS curve dynamics, such an announcement generates an increase in the current output gap $\left(x_{t}=-1 / \sigma e_{t+N, t}>0\right)$ and, by moving the IS curve forward, also the expected output gaps increase $\left(x_{t+j \mid t}=-1 / \sigma e_{t+N, t}>0\right)$. Because inflation is purely forward looking, we have that inflation today and tomorrow increase. In particular, current and expected inflation is a decreasing function in the horizon, i.e.

$$
\pi_{t+j \mid t}=-\kappa / \sigma \frac{1-\beta^{N+1-j}}{1-\beta} e_{t+N, t}
$$

for $j \leq N$ and expected inflation is zero behind the announcement horizon, since agents expect the central bank to revert to the optimal rule, i.e., $\pi_{t+j \mid t}=0$ for $j>N$. Accordingly, the nominal interest rates at various maturities are given by

$$
\begin{aligned}
i_{t+j, t} & =r_{t+j, t}^{n}-\kappa / \sigma \frac{1-\beta^{N-j}}{1-\beta} e_{t+N, t} \text { for } j<N, \\
i_{t+N, t} & =r_{t+N, t}^{n}+e_{t+N, t},
\end{aligned}
$$

since $\pi_{t+N+1, t}=0$; i.e., inflations expectations are zero behind the announcement horizon (agents expect the central bank to revert to the optimal zero inflation rule after $t+N$ periods). In the standard New Kenynesian model, the natural rate of interest is a linear combination of the structural exogenous shocks that describe technology and preferences. The expectations about the future exogenous shocks are typically linear projections of the 
current fundamentals of the economy, i.e., the current realization of the shocks. Therefore, one can express the $t+j$ step ahead forecast of the natural rate of interest, $r_{t+j, t}^{n}$, as a linear projection of the current value of the fundamentals:

$$
r_{t+j, t}^{n}=\phi_{j}^{\prime} \Omega_{t},
$$

where $\Omega_{t}$ is the column vector collecting the current realizations of the fundamentals and $\phi_{j}$ is a column vector of convoluted parameters that projects the fundamentals out-of-sample. Therefore, the $t+j$ step ahead expected nominal rates are given by

$$
i_{t+j, t}=\phi_{j}^{\prime} \Omega_{t}-\psi_{j} e_{t+N, t}
$$

where $\psi_{j}=\kappa / \sigma \frac{1-\beta^{N-j}}{1-\beta}>0$ for $j=1, . ., N-1$ and $\psi_{N}=-1$. The slope of the term structure of interest rates can be expressed as the difference between long and short rates:

$$
i_{t+N, t}-i_{t+j, t}=\left(\phi_{N}-\phi_{j}\right)^{\prime} \Omega_{t}+\left(1+\psi_{j}\right) e_{t+N, t} .
$$

Therefore, in this simple three-equation NK model we can derive analytically the sign of the correlation between the slope of the term structure of interest rates and inflation expectations conditional on a monetary policy shocks:

$$
\operatorname{corr}\left(\left(i_{t+N, t}-i_{t+j, t}\right), \pi_{t+j, t} \mid e_{t+N, t}\right)=-\kappa / \sigma \frac{1-\beta^{N+1-j}}{1-\beta}\left(1+\psi_{j}\right) \sigma_{e}^{2}<0,
$$

where we assume that shocks to monetary policy and to fundamentals are independent. Models with more shocks and more nominal and/or real frictions behave very similarly. The magnitudes are different, but the sign implications are unaffected (see the Appendix A.2 for details). In a narrow window around the monetary policy announcement, it is reasonable to assume that there are no major variations in the values of the fundamentals. Therefore, in a model with perfect information, the unconditional correlation between the slope of the term structure of rates and inflation expectations coincides with a correlation conditional on monetary policy announcements. Moreover, all the variation in the slope of the term structure of nominal interest rates is attributable to the monetary policy announcements. With imperfect or dispersed information, this is no longer true. During the press conference, the private sector might revise their estimates of the fundamentals based on the monetary authority's communications. However, a credible announcement about a Odyssean commitment to future accommodation (i.e. a future positive demand shock), that is understood by the public as such, should reduce the slope of the interest rate term structure and should lead to an increase of inflation expectations. The latter can be seen as a necessary condition. If this does not happen, then the shock is not an Odyssean forward guidance shock. While one could impose more restrictions and narrow the identification set down, this condition is relatively uncontroversial and common to a wide variety of structural models with different types of frictions. 


\subsection{ECONOMETRIC IDENTIFICATION}

When using only the information from the variations in the OIS futures contracts, we are unable to tease apart Delphic and Odyssean forward guidance shocks. However, if we also introduce in the data set the measures of inflation expectations, we can exploit the sign of the conditional correlation as a device to identify the Odyssean shocks. Toward this aim, we pool together variations in the OIS futures and in the ILS, and extract three factors. We rotate the factors so that the second factor and the third factor do not influence the current-month OIS. Moreover, we assume that the second factor has a positive impact on the one-year OIS futures contract and on the five-year ILS, and that the third factor has a positive impact on the one-year OIS futures contract and negative on the five-year ILS. ${ }^{9}$ The second factor can be interpreted as a Delphic forward guidance shock and the third factor as an Odyssean forward guidance shock.

More precisely, let $Y$ be a $T \times k$ matrix containing the OIS and ILS variations. We assume that the data are generated by this factor structure:

$$
Y=F \Lambda^{\prime}+e=\eta(\Lambda H)^{\prime}+e .
$$

Without loss of generality, assume that the ordering of the variables in the $Y$ matrix is as follows: current-month OIS, one-year ahead OIS, five-year ILS and then all the remaining variables. Our identification is achieved assuming that $\Lambda H$ has the following structure:

$$
\left(\begin{array}{c}
\Delta_{30 m} O I S_{1 M, t} \\
\Delta_{30 m} O I S_{1 Y, t} \\
\Delta_{2 d} I L S_{5 Y, t} \\
\vdots \\
*
\end{array}\right)=\left(\begin{array}{ccc}
* & 0 & 0 \\
* & + & + \\
* & + & - \\
\vdots & \vdots & \vdots \\
* & * & *
\end{array}\right)\left(\begin{array}{c}
\eta_{t}^{t} \\
\eta_{t}^{d} \\
\eta_{t}^{o}
\end{array}\right)+e_{t} .
$$

Figure 2 reports the target factor (black line in the top panel) and path factor (black line in the central panel) using only OIS information. Figure 2 also reports the target, Delphic and Odyssean factors using OIS and ILS. The target (path, Delphic, and Odyssean) factor is normalized so that it generates a $1 \%$ increase in the one-month (one-year) OIS futures. The target factors are similar when using only OIS or OIS and ILS. The central panel reports the path factor and the Delphic component of monetary policy announcements and shows the degree of comovement between the two series. ${ }^{10}$ The bottom panel of Figure 2 reports the estimated Odyssean shocks and highlights a number of episodes where the realized shocks were larger than the standard deviations (in absolute values). In particular, we focus our attention on the following press conference days

07/2013 Odyssean factor -4.8 basis points. President Draghi announced for the first time forward guidance, according to his introductory statement, "[The GC] expects the key ECB interest rate to remain at present or lower levels for an extended period of time."

\footnotetext{
${ }^{9}$ Details on the identification with zero and sign restrictions can be found in the appendix A.1.

10 The correlation between the path factor and the Delphic factor is 0.70 and the correlation between the path factor and the Odyssean factor is 0.46.
} 
01/2015 Odyssean factor -4.9 basis points. President Draghi announced the QE package. He stated "First, [the GC] decided to launch an expanded asset purchase programme, encompassing the existing purchase programmes for asset-backed securities and covered bonds. Under this expanded programme, the combined monthly purchases of public and private sector securities will amount to Euro 60 billion. They are intended to be carried out until end-September 2016 and will in any case be conducted until we see a sustained adjustment in the path of inflation which is consistent with our aim of achieving inflation rates below, but close to, $2 \%$ over the medium term".

10/2015 Odyssean factor -6.3 basis points. President Draghi anticipated that the QE package might be adjusted. "In this context, the degree of monetary policy accommodation will need to be re-examined at our December monetary policy meeting, when the new Eurosystem staff macroeconomic projections will be available. The Governing Council is willing and able to act by using all the instruments available within its mandate if warranted in order to maintain an appropriate degree of monetary accommodation. In particular, the Governing Council recalls that the asset purchase programme provides sufficient flexibility in terms of adjusting its size, composition and duration."

12/2015 Odyssean factor +10 basis points. President Draghi announced two monetary measures: (1) cutting of interest rates on deposit facilities and (2) extending the duration of the asset purchase program until March 2017. The Odyssean number seems inconsistent with the announcement about monetary accommodation. However, market participants were expecting a more aggressive move. As it appears in the transcripts of the monetary policy press conference, questions about the weakness of monetary policy actions were raised by the press conference participants. For example, one participant said, "And my second question is, it seems like what you've done is a little bit on the low end of the range of what the financial markets had expected, in terms of your stimulus package today. It seems like the initial reaction in the financial markets bears this point. Why didn't you do more, given how much you've warned about the risks of low inflation? Why didn't you raise the monthly purchase amount? Why didn't you cut the deposit rate more?" And similarly another said, "You've just explained your reasoning, but nevertheless, financial markets appear to be disappointed. So what is the reason there? Do you think that something went wrong in your communication in the run-up to the decision? Did you perhaps overestimate your ability to convince fellow policy-makers to decide something even more aggressive? Or do financial markets not understand yet how powerful these measures actually are?"

Contrary to the path factor, our measure of Odyssean shocks is able to identify a number of recent key events that appear relevant from a narrative viewpoint. Moreover, it seems that the Delphic shocks are more important in the central part of our sample and less so in the recent episodes. As mentioned before, we are studying an eventful sample period, encompassing large swings in oil prices preceding the Great Recession, the global financial 
turmoil of 2009, the euro area sovereign debt crisis, and the short term rates hitting the effective lower bound and a novel set of unconventional monetary policy tools implemented by the ECB in response. To this list we would add the change in the ECB communications at the monetary policy press conference, moving from a "no pre-commitments" attitude toward more forward-looking statements and commitments.

What are the impacts of the monetary policy announcements on financial instruments? Are they different when considering a generic announcement (path factor) or an Odyssean one? We considered various dependent variables and regressed them on the different measures of monetary policy shocks. We considered nominal interest rates and inflation rates at various horizons and the real rates by taking the difference between the nominal spot rates and the inflation spot rates. We considered daily figures for the borrowing rates for non-financial corporations and for banks from Gilchrist and Mojon (2017). These rates correspond to the effective yields on the zero-coupon euro-denominated bonds issued by banks and by non-financial corporations in the euro area. We also included in our analysis the log of euro area (overall and only banks') stock market prices. We considered the two-day variations on the day of the press conference and regress them in turn on a constant, target and path factor and on a constant, target, Delphic and Odyssean factor. Table 5 reports the estimated coefficients on the first (columns 3-5) and second (columns 6-9) regression. There are a number of things worth highlighting. First, the fit improves using the target, Delphic, and Odyssean shocks as opposed to using only the target and path factors. Second, the path factor moves the real forward rates up through an increase in the nominal rates, which largely offsets the positive movement of expected inflation rates. The Odyssean factor moves the real rates in the same direction for a different reason - expected inflation rates decline and nominal rates increase. The impact of the Delphic shocks on the real rates is found to be muted, as the movements in expected nominal rates are offset by the increase in expected inflation. The impact of these factors on stock market prices is interesting. While the path factor does not have a significant impact on the movement of stock market prices, the Delphic and Odyssean shocks generate significant variations with the expected signs. Interestingly, regardless of the nature of the shocks - whether there is an increase in the path factor, or in the Delphic factor, or in the Odyssean factor, an announcement about future tightening exerts an upward pressure on the borrowing costs faced by non-financial corporations and by banks. So, monetary policy shocks do not affect only financial markets instruments but also translate into an increase in the borrowing costs faced by real side of the economy. In the next section, we study how long the impact of Delphic and Odyssean shocks last. 


\begin{tabular}{|c|c|c|c|c|c|c|c|c|}
\hline & & $t$ & $p$ & $\operatorname{Adj} R^{2}$ & $t$ & $d$ & $o$ & $\operatorname{Adj} R^{2}$ \\
\hline \multirow{5}{*}{ Nominal Rates } & $1 \mathrm{~m}$ & $0.78^{* * *}$ & -0.03 & 0.34 & $0.58^{* * *}$ & 0.10 & -0.08 & 0.13 \\
\hline & $2 y$ & $0.87^{* * *}$ & $1.16^{* * *}$ & 0.44 & $1.57^{* * *}$ & $1.60^{* * *}$ & $0.49^{* *}$ & 0.59 \\
\hline & $3 y$ & $0.58^{* *}$ & $1.13^{* * *}$ & 0.48 & $1.45^{* * *}$ & $1.54^{* * *}$ & $0.51^{* *}$ & 0.54 \\
\hline & $5 y$ & 0.37 & $0.93^{* * *}$ & 0.38 & $0.90^{* * *}$ & $1.42^{* * *}$ & $0.49^{* *}$ & 0.46 \\
\hline & $10 y$ & -0.09 & $0.50^{* * *}$ & 0.11 & 0.18 & $0.88^{* * *}$ & 0.01 & 0.17 \\
\hline \multirow{7}{*}{ Inflation } & $2 y$ & $-0.41^{*}$ & $0.34^{* * *}$ & 0.07 & $-1.08^{* * *}$ & $1.52^{* * *}$ & $-0.66^{* * *}$ & 0.85 \\
\hline & $3 y$ & $-0.53^{* * *}$ & $0.33^{* * *}$ & 0.12 & $-0.99^{* * *}$ & $1.32^{* * *}$ & $-0.63^{* * *}$ & 0.92 \\
\hline & $5 y$ & -0.08 & $0.24^{* * *}$ & 0.09 & -0.08 & $0.87^{* * *}$ & $-0.83^{* * *}$ & 0.86 \\
\hline & $10 y$ & 0.12 & $0.17^{* * *}$ & 0.06 & $0.33^{* * *}$ & $0.61^{* * *}$ & $-0.96^{* * *}$ & 0.88 \\
\hline & $1 y 1 y$ & $-1.05^{* * *}$ & 0.26 & 0.06 & $-1.85^{* * *}$ & $1.46^{* * *}$ & $-0.96^{* * *}$ & 0.42 \\
\hline & $2 \mathrm{y} 2 \mathrm{y}$ & -0.06 & 0.04 & -0.01 & -0.02 & $0.47^{* * *}$ & $-0.98^{* * *}$ & 0.37 \\
\hline & $5 y 5 y$ & $0.31^{* *}$ & 0.09 & 0.04 & $0.75^{* * *}$ & $0.35^{* * *}$ & $-1.09^{* * *}$ & 0.60 \\
\hline \multirow{4}{*}{ Real Rate } & $2 y$ & $1.20^{* * *}$ & $0.76^{* * *}$ & 0.37 & $2.65^{* * *}$ & 0.08 & $1.14^{* * *}$ & 0.52 \\
\hline & $3 y$ & $1.08^{* * *}$ & $0.79^{* * *}$ & 0.36 & $2.44^{* * *}$ & 0.21 & $1.13^{* * *}$ & 0.45 \\
\hline & $5 y$ & $0.42^{*}$ & $0.69^{* * *}$ & 0.27 & $0.97^{* * *}$ & $0.56^{* * *}$ & $1.32^{* * *}$ & 0.31 \\
\hline & $10 \mathrm{y}$ & -0.23 & $0.33^{* * *}$ & 0.05 & -0.17 & $0.28^{*}$ & $0.97^{* * *}$ & 0.11 \\
\hline \multirow{2}{*}{ Borrowing rates } & NFC & 0.22 & $0.77^{* * *}$ & 0.25 & $0.51^{* *}$ & $0.85^{* * *}$ & $0.75^{* * *}$ & 0.31 \\
\hline & Banks & 0.13 & $0.70^{* * *}$ & 0.30 & $0.54^{* *}$ & $0.68^{* * *}$ & $0.94^{* * *}$ & 0.31 \\
\hline \multirow{2}{*}{$(\log )$ STOXX } & All & -0.02 & 0.05 & 0.00 & 0.01 & $0.14^{* * *}$ & $-0.29^{* * *}$ & 0.15 \\
\hline & Banks & -0.01 & 0.07 & 0.00 & 0.01 & $0.21^{* * *}$ & $-0.33^{* * *}$ & 0.11 \\
\hline
\end{tabular}

Table 5: Regression estimating responses of the revisions to the target and path and to the target, Delphic, and Odyssean factors. The real rates are computed as the difference between the nominal and inflation rates. $t$ stands for target factor, $p$ for path factor, $d$ for Delphic factor, and $o$ for Odyssean factor. One, two, and three asterisks indicate statistical significance at $10 \%, 5 \%$, and $1 \%$ respectively. The target (path, Delphic, and Odyssean) factor is normalized so that it generates a $1 \%$ increase in the one-month (one-year) OIS futures. 


\subsection{Persistence of Monetary Policy announcement}

To get a sense of the persistence of the effects of Delphic and Odyssean shocks, we run a series of daily regressions at multiple horizons of the form

$$
y_{t-1+h}=\alpha_{h}+\beta_{h}(L) y_{t-1}+\gamma_{h} \eta_{t}^{j}+\epsilon_{t}^{(h)},
$$

where each forecast horizon $h$ is associated with a different regression; $y$ denotes the variable of interest at a given maturity; $t$ indexes business days; $\eta_{t}^{j}$ denotes the monetary policy surprises as estimated earlier in the paper (and is set equal to zero on non-ECB announcement days); $\epsilon_{t}^{(h)}$ is a residual and $\alpha_{h}, \beta_{h}$, and $\gamma_{h}$ are parameters that may vary across regressions $h$. This is essentially Jordá (2005)'s "direct projections" method of estimating impulse response functions, with a lag length of zero for the lagged endogenous variable $y$ on the right-hand side. We estimate that the coefficients $\alpha_{h}$ and $\beta_{h}$ are essentially always close to zero and one, respectively. Of course, for longer horizons, there will also be a greater amount of nonmonetary-policy news that impacts swaps, so the residuals and standard errors surrounding the coefficient estimates will tend to be larger. Figure 3 plots the results of these regressions for the two years, the two years in two years and the five years in five years ILS; the nonfinancial corporation borrowing rates; and the (log of) stock market prices. The solid blue line in each panel plots the point estimates of $\gamma_{h}$ as a function of horizon $h$, and gray area indicates the Newey-West (1987) \pm 1.96 -standard-error bands around those point estimates, allowing for $h-1$ lags of autocorrelation.

The effects of the target shocks are transitory and disappear after few days. Delphic and Odyssean shocks have persistent effects on the variables of interest, ranging from weeks to months. In particular, Delphic shocks have long lasting effects on inflation expectations and stock market prices that do not disappear within a quarter. While Odyssean shocks' effects are less persistent, their dynamic transmission is found to last for one to two months. While we impose signs restrictions only on the contemporaneous correlation between nominal and inflation rates, we find that the signs of the impact of Delphic and Odyssean shocks found with the two-day variations hold also at different horizons.

By imposing an additional restriction on the correlation between the expected nominal rates and expected inflation, we constructed an observable proxy of monetary policy news shock (Odyssean factor) with desirable properties. It is consistent with a narrative description of the latest episodes of the ECB monetary policy announcements. It impacts daily financial instruments in accordance with our priors for an announcement about future monetary policy tightening (or accommodation) and displays some form of persistence that goes beyond the immediate business days following the monetary policy announcements at the press conference. 


\begin{tabular}{c|ccccccc} 
& Target & Path & Adj $R^{2}$ & Target & Delphic & Odyssean & Adj $R^{2}$ \\
\hline & & & & & & & \\
$G D P_{\text {current } Y}$ & -0.73 & 0.01 & -0.01 & -3.12 & 1.42 & 0.01 & -0.01 \\
$G D P_{\text {next } Y}$ & -0.51 & 0.50 & -0.01 & -0.03 & $1.43^{* *}$ & $-1.98^{* *}$ & 0.02 \\
$\pi_{\text {current } Y}$ & 0.04 & -0.17 & -0.01 & -0.34 & -0.38 & 0.69 & -0.02 \\
$\pi_{\text {next } Y}$ & -0.15 & 0.13 & -0.01 & -0.33 & $0.78^{* *}$ & $-1.06^{*}$ & 0.03 \\
\hline & & & & & & & \\
\hline
\end{tabular}

Table 6: Regression estimating the monthly variation Consensus Economic forecasts on the factors. OLS estimates and statistical significance, 1(5 and 10) $\%$ indicated with $* * *(* *$ and $*)$ with robust SE.

\subsection{Impact on SuRvey Expectations}

Table 6 reports the regressions estimating the monthly variations of GDP and inflation expectations from Consensus Economics on various factors (and a constant). In particular, we considered the following specifications:

$$
\Delta^{m} F_{h, t}^{\text {consenus }}=\alpha_{0}+\alpha_{1} f_{t}^{\text {Target }}+\alpha_{2} f_{t}^{\text {Path }}+e_{t}
$$

and

$$
\Delta^{m} F_{h, t}^{\text {consenus }}=\beta_{0}+\beta_{1} f_{t}^{\text {Target }}+\beta_{2} f_{t}^{\text {Delphic }}+\beta_{3} f_{t}^{\text {Odyssean }}+v_{t},
$$

where $h=$ current $Y$, next $Y$. Overall, the fit is very poor. It improves marginally for the next-year forecasts when we account for the Delphic and Odyssean components, i.e the adjusted $R^{2}$ improves from -0.01 to $0.03 / 0.02$. However, and more importantly, the signs on the Delphic and Odyssean factors are in line with the identification using market-based inflation expectations. These regressions focus only on contemporaneous impact effects. In the next section, we offer a quantitative estimate of the dynamic propagation of Odyssean and path shocks on output and prices and on survey expectations about output growth and inflation.

\section{The MACROECONOMIC IMPACT OF ODYSSEAN MONETARY POLICY SURPRISES}

The aim of this section is to quantify the dynamic impacts of the identified measures of monetary policy announcements on macroeconomic variables. A popular way to measure the dynamic transmission of a macroeconomic shock in general and a monetary policy shock in particular is by means of VAR models (see Ramey (2016) for an overview). VAR models assume that the joint comovements of the macroeconomic variables can be described by linear lag structure of order $p$, which takes the following form:

$$
y_{t}=\Phi_{0}+\Phi_{1} y_{t-1}+\ldots \Phi_{p} y_{t-1}+e_{t} e_{t} \sim N(0, \Sigma)
$$

where $y_{t}$ is a vector that contains the observable variables and $\epsilon_{t}$ is a vector of a normal zero mean identically distributed and serially uncorrelated shocks with $\Sigma=E\left(\epsilon_{t} \epsilon_{t}^{\prime}\right)$. Note 
that $\Phi_{0}, \Phi_{1}, \ldots, \Phi_{p}$ are matrices of appropriate dimensions describing the dynamics of the system. We can rewrite the VAR in a companion form, i.e., $y_{t}=x_{t}^{\prime} \Phi+e_{t}$, where $x_{t}=$ $\left[y_{t-1}^{\prime}, \ldots, y_{t-p}^{\prime}, 1\right]^{\prime}$ with $\Phi$ being the companion form matrix, and estimate the parameters of interest either with classical estimators or using a Bayesian approach. Under the assumption of normal distribution of the residuals, the reduced-form VAR is compatible with several structural representations where reduced-form shocks can be expressed as linear combination of structural uncorrelated innovation, i.e.

$$
e_{t}=\Omega \nu_{t}
$$

where $\Omega \Omega^{\prime}=\Sigma, E\left(\nu_{t} \nu_{t}^{\prime}\right)=I_{n}$. Since the likelihood of the data is flat along the $\Omega$ matrix dimension, additional restrictions are need to identify the structural shocks.

Following Mertens and Ravn (2013) and Stock and Watson (2012), we map the reducedform VAR residuals with the structural shock of interest by instrumenting the VAR residuals (observable) with a measurable proxy for the structural shock (unobservable). In our context, the proxy f monetary policy shock is given by the path factor and the Odyssean shocks extracted from the high-frequency data as discussed in previous sections. Gertler and Karadi (2015) applied this methodology to study the transmission of FOMC announcements on prices, output and the credit spread using an small scale VAR estimated with classical inference. Similarly, Miranda-Agrippino (2015) used this framework to measure the transmission of orthogonal monetary policy surprises in the United Kingdom. The novelty of this paper is to isolate the effect of the Odyssean component of monetary policy announcements and then measure its impact.

The basic idea of the structural VAR with an external instrument is that the monetary policy shock in the structural VAR is identified as the predicted value in the population regression of the instrument on the reduced-form VAR residuals. For this result to hold, the instrument needs to be valid; i.e., it needs to be relevant (correlated with the unobserved monetary policy shock of the VAR) and exogenous (uncorrelated with the other shocks). This approach allows us to recover the the first column of the rotation matrix $\Omega$ and thus to recover impulse responses and the transmission mechanism. More formally, let $m_{t}$ be the time series proxy for the unobserved structural shock. Assume without loss of generality that the proxy is linked to the first shock as follows

$$
\begin{aligned}
E\left(\nu_{t} m_{t}\right) & =[\rho, 0, \ldots, 0]^{\prime}, \\
E\left(\Omega \nu_{t} m_{t}\right) & =\Omega[\rho, 0, \ldots, 0]^{\prime}, \\
E\left(e_{t} m_{t}\right) & =\rho\left[\Omega_{11}, \Omega_{2: N, 1}^{\prime}\right]^{\prime} .
\end{aligned}
$$

Assuming that the first-reduced form shock is related to the observed proxy, we can partition the two sets of relationships and obtain

$$
E\left(e_{2, t} m_{t}\right) E\left(e_{1, t} m_{t}\right)^{-1}=\Omega_{11}^{-1} \Omega_{2: N, 1}
$$


where the second equation can be estimated using the sample analog, since $m_{t}$ is observable, $e_{t}$ is observable conditional on $\Phi$ and $\Sigma$ and they are both stationary. This restriction, coupled with the fact that $\Omega \Omega^{\prime}=\Sigma$, gives rise to a set of equations that up to a sign normalization uniquely pin down the first column of the rotation matrix. The econometric approach works as follows. We first run the VAR ordinary least square (OLS) regression to obtain $\Phi$ and $\Sigma$. We then isolate the variation in the reduced-form residual of the policy indicator that is attributable to the proxy. We then regress the remaining reduced-form residuals on the fitted value of the first regression. To obtain the confidence bands around the impulse response we follow Mertens and Ravn (2013) and run a wild bootstrap of the VAR residuals.

The VAR data set consists of survey data measuring private sector expectations and of macroeconomic data. We include as monetary policy instrument the difference between the 12-months and the three-month EONIA swaps, which is a measure of the slope of the term structure of rates; we instrument the residuals of this equation with our proxies for monetary policy surprises. We then include the seasonally adjusted (log) industrial production index (excluding construction), the (log) HICP excluding energy and food prices and the Gilchrist and Mojon (2017) credit spread. We also include survey measures of expectations, i.e., the Consensus forecasts for next year's GDP growth and next year's inflation rate. The data series are observed at monthly frequencies and span the period from January 2002 until January 2016.

Figures 4 report the estimated impulse responses to the Odyssean monetary policy announcement and a generic monetary policy announcement that does not distinguish between the Delphic and Odyssean components, i.e., the path factor. Both announcements are normalized to generate a future monetary policy tightening, which widens the spread between the 12- and three-month-ahead forecast of the short-term nominal interest rate, generating a steepening of the slope of the term structure. A generic announcement lifts the expectations about inflation and output growth, suggesting a strong signaling component (panels (i) and $(\mathrm{k})$ ). In contrast, the Odyssean announcement about monetary policy tightening depresses the agents' expectations about inflation and output growth (panels (j) and (l)). While both effects are short lasting, the sign impact is consistent with a credible announcement about a commitment to future tightening. The sign implication on output and prices are similar. A generic announcement about monetary policy tightening generates an initial drop in industrial production, which bounces back shortly after. Core prices move up permanently and significantly. This core prices result is difficult to rationalize as a standard transmission mechanism of a future monetary policy tightening, unless we acknowledge a strong signaling effect of monetary policy. The dynamic transmission of the Odyssean shock does not lead to this interpretation. Both actual prices and quantities (with a delay), as well as expectations about them, move in line with a "well-understood" commitment to a future monetary policy restrictive stance. This gives additional credit to the identification strategy we used 
to identify future monetary policy shocks.

\section{Conclusions}

We study the Delphic and Odyssean components of forward guidance shocks. We propose an approach to separately identify them, and we measure their dynamic impact on the euro area macroeconomic aggregates and the expectations about future prospects. Two findings emerge. First, in the central part of our sample the ECB announcements were read as a signal about the economic conditions and in latest episodes they have been interpreted as a commitment device on future monetary policy accommodation. Second, we showed that euro area macroeconomic aggregates responded very differently to a path factor impulse compared with an Odyssean monetary policy impulse. In particular, in the former case an announcement of tightening is expansionary. In the latter, an announcement about future monetary policy tightening interpreted as Odyssean decreases industrial production, core prices and expectations about inflation and output growth.

\section{REFERENCES}

Banbura, M. and Modugno, M.: 2014, Maximum Likelihood Estimation Of Factor Models

On Datasets With Arbitrary Pattern Of Missing Data, Journal of Applied Econometrics 29(1), 133-160.

Bernanke, B. S.: 2013, Communication and monetary policy.

Campbell, J. R., Evans, C. L., Fisher, J. D. and Justiniano, A.: 2012, Macroeconomic Effects of Federal Reserve Forward Guidance, Brookings Papers on Economic Activity 44(1 (Spring), 1-80.

Campbell, J. R., Fisher, J. D., Justiniano, A. and Melosi, L.: 2017, Forward Guidance and Macroeconomic Outcomes Since the Financial Crisis, NBER Macroeconomics Annual 2016, Volume 31, NBER Chapters, National Bureau of Economic Research, Inc.

Carlstrom, C. T., Fuerst, T. S. and Paustian, M.: 2015, Inflation and output in New Keynesian models with a transient interest rate peg, Journal of Monetary Economics 76(C), 230243.

D'Amico, S. and King, T. B.: 2015, What Does Anticipated Monetary Policy Do?, Working Paper Series WP-2015-10, Federal Reserve Bank of Chicago.

Del Negro, M., Giannoni, M. and Patterson, C.: 2012, The forward guidance puzzle, Staff Reports 574, Federal Reserve Bank of New York.

URL: https://ideas.repec.org/p/fip/fednsr/574.html 
Garcia, J. A. and Werner, T.: 2010, Inflation risks and inflation risk premia, Working Paper Series 1162, European Central Bank.

Gertler, M. and Karadi, P.: 2015, Monetary Policy Surprises, Credit Costs, and Economic Activity, American Economic Journal: Macroeconomics 7(1), 44-76.

Gilchrist, S. and Mojon, B.: 2017, Credit Risk in the Euro Area, Economic Journal .

Gürkaynak, R. S., Sack, B. and Swanson, E.: 2005a, Do Actions Speak Louder Than Words? The Response of Asset Prices to Monetary Policy Actions and Statements, International Journal of Central Banking 1(1).

Gürkaynak, R. S., Sack, B. and Swanson, E.: 2005b, The Sensitivity of Long-Term Interest Rates to Economic News: Evidence and Implications for Macroeconomic Models, American Economic Review 95(1), 425-36.

Jardet, C. and Monks, A.: 2014, Euro Area monetary policy shocks: impact on financial asset prices during the crisis?, Working papers 512, Banque de France.

Jordá, O.: 2005, Estimation and Inference of Impulse Responses by Local Projections, American Economic Review 95(1), 161-182.

Karadi, P. and Jarocinsky, M.: 2018, Deconstructing monetary policy surprises: the role of information shocks, Working Paper Series 2133, European Central Bank.

Kiley, M.: 2016, Policy Paradoxes in the New-Keynesian Model, Review of Economic Dynamics 21, 1-15.

Kuttner, K. N.: 2001, Monetary policy surprises and interest rates: Evidence from the Fed funds futures market, Journal of Monetary Economics 47(3), 523-544.

McKay, A., Nakamura, E. and Steinsson, J.: 2015, The Power of Forward Guidance Revisited, NBER Working Papers 20882, National Bureau of Economic Research, Inc.

Mertens, K. and Ravn, M. O.: 2013, The Dynamic Effects of Personal and Corporate Income Tax Changes in the United States, American Economic Review 103(4), 1212-47.

Miranda-Agrippino, S.: 2015, Unsurprising Shocks: Information, Premia, and the Monetary Transmission, Discussion Papers 1613, Centre for Macroeconomics (CFM).

Miranda-Agrippino, S. and Ricco, G.: 2017, The Transmission of Monetary Policy Shocks, Working Paper Series 2133, Bank of England.

Nakamura, E. and Steinsson, J.: 2013, High Frequency Identification of Monetary NonNeutrality, NBER Working Papers 19260, National Bureau of Economic Research, Inc. 
Nakamura, E. and Steinsson, J.: 2017, High frequency identification of monetary nonneutrality, Quarterly Journal of Economics forth.

Piazzesi, M.: 2002, The Fed and Interest Rates - A High-Frequency Identification, American Economic Review 92(2), 90-95.

Ramey, V. A.: 2016, Macroeconomic Shocks and Their Propagation, NBER Working Papers 21978, National Bureau of Economic Research, Inc.

Romer, D. H. and Romer, C. D.: 2000, Federal Reserve Information and the Behavior of Interest Rates, American Economic Review 90(3), 429-457.

Smets, F. and Wouters, R.: 2007, Shocks and Frictions in US Business Cycles: A Bayesian DSGE Approach, American Economic Review 97(3), 586-606.

Stock, J. H. and Watson, M. W.: 2012, Disentangling the Channels of the 2007-09 Recession, Brookings Papers on Economic Activity 44(1 (Spring), 81-156. 


\section{A Appendix}

\section{A.1 IDENTIFICATION WITH ZERO AND SIGN RESTRICTIONS}

Let $X$ be a $T \times k$ matrix containing the OIS and ILS variations. We assume that the data are generated by the following factor structure:

$$
X=F \Lambda^{\prime}+e
$$

where $F$ is a $T \times 3$ matrix containing the unobserved factors, $\Lambda$ is a $k \times 3$ matrix of factor loadings, $e$ is a matrix of i.i.d. normal shocks of appropriate dimension. We extract factors and loadings using principal component analysis (PCA). We rotate the factor using an orthonormal matrix $H$ (i.e. $H H^{\prime}=H^{\prime} H=I$ ) so that

$$
Z=F H
$$

Substituting the latter equation into the factor model we obtain

$$
X=Z(\Lambda H)^{\prime}+e
$$

Without loss of generality, assume that the ordering of the variables in the $X$ matrix is the following: current-month OIS, one-year ahead OIS, five-year ILS, and then all the remaining variables. Our identification is achieved assuming that $\Lambda H$ has the following structure

$$
\Lambda H=\left(\begin{array}{ccc}
* & 0 & 0 \\
* & + & + \\
* & + & - \\
\vdots & \vdots & \vdots \\
* & * & *
\end{array}\right),
$$

where an asterisk indicates a number. Imposing the zero and sign restrictions on $\Lambda H$ is equivalent to imposing the zero and sign restrictions on $\Lambda_{3: 3} H$, which is the top $3 \times 3$ submatrix of $\Lambda H$. In order to obtain the desired rotation, we proceed in two steps. We first obtain the Cholseky decomposition of $\Lambda_{3: 3} \widetilde{H}$, i.e.

$$
\Lambda_{3: 3} \widetilde{H}=\left(\begin{array}{ccc}
* & 0 & 0 \\
* & * & 0 \\
* & * & *
\end{array}\right)
$$

and recover $\widetilde{H}$ by

$$
\widetilde{H}=\Lambda_{3: 3}^{-1} \operatorname{chol}\left(\Lambda_{3: 3} \Lambda_{3: 3}^{\prime}\right),
$$

given that $\Lambda_{3: 3} \Lambda_{3: 3}^{\prime}=\Lambda_{3: 3} \widetilde{H} \widetilde{H}^{\prime} \Lambda_{3: 3}^{\prime}$. We then rotate the $\widetilde{H}$ matrix using the Givens rotation such that the structure of $\Lambda H$ is preserved. More formally,

$$
\widetilde{H} Q(\theta)=H,
$$

where

$$
Q=\left(\begin{array}{ccc}
1 & 0 & 0 \\
0 & \cos \theta & -\sin \theta \\
0 & \sin \theta & \cos \theta
\end{array}\right)
$$


This rotation will leave unchanged the first row and column of $\Lambda_{3: 3} \widetilde{H}$, thus preserving the zero restrictions. We consider a grid of values for $\theta$ ranging from 0 to $\pi$ with a 0.05 step. For each of these values we keep the rotation if the signs in $\Lambda \widetilde{H} Q(\theta)$ are satisfied. We then consider the average of the accepted rotations, $H_{m}=\Lambda_{3: 3}^{-1} 1 / J \sum_{j}^{J} \Lambda_{3: 3} \widetilde{H} Q\left(\theta^{(j)}\right)$.

\section{A.2 Extension: Smets And Wouters (2007) Model}

This section provides a quantitative exploration of the correlation between the slope of the term structure of interest rates and inflation expectations conditional on monetary policy announcements in a medium-scale DSGE model. We consider the baseline version of the Smets and Wouters (2007) model (henceforth, SW). This model is selected because of its widespread use for policy analysis among academics and policymakers and because it is frequently adopted to study cyclical dynamics and their sources of fluctuations in developed economies. We retain all the nominal and real frictions originally present in the model.

Since we cannot solve the model analytically, we need to rely on specific exercises. We assume that the monetary policy authority announces that in one year's time the policy (nominal) interest rate $r_{t}$ will be higher. More precisely, since the SW model is quarterly, we postulate that the nominal short term interest rate will be increased by five basis points in four time periods. We compute the trajectories of inflation expectations, $E_{t} \pi_{t+j}$, and of the slope of the term structure of interest rates, $E_{t} r_{t+j}-r_{t}$ (where $r_{t}$ is the short-run nominal interest rate), in response to this monetary policy tightening. In order to show that these results are not driven by a specific parameter value combination, we draw random numbers from the priors indicated in SW.

In Figure 5 the gray areas reports all the possible trajectories for the slope of the the term structure of rates, $E_{t} r_{t+4}-r_{t}$, and the inflation expectations, $E_{t} \pi_{t+j}$ for $j+1, \ldots, 4$, of such announcements. Following the announcement of tightening, the slope of the interest rate term structure increases and inflation expectations rise. Hence, the correlation conditional on the monetary policy announcement is negative.

\section{A.3 Information Asymmetries and Central Bank Expectations REVISIONS.}

Some authors argue that the central bank can process more information relative to the private sectors. Agents might then close the information asymmetry gap during the conference press and revise their expectations about the future. If this is the case, then variations in interest rate do not reflect exogenous monetary policy shocks and they are rather the result of information sets adjustments. If we had an empirical measure of information asymmetry, then we could clean the monetary policy surprises extracted from interest rate futures variations from the adjustments in private and central bank information sets. 


\begin{tabular}{|c|c|c|c|c|c|c|c|}
\hline & \multirow[t]{2}{*}{$\mathrm{R} 2$} & \multicolumn{5}{|c|}{ P-values } & \multirow[t]{2}{*}{$\mathrm{F}$ test } \\
\hline & & Const & HICP & $\operatorname{HICP}(+1)$ & RGDP & $\operatorname{RGDP}(+1)$ & \\
\hline & & \multicolumn{6}{|c|}{ Lagged $k=1$} \\
\hline target & 0.05 & 0.38 & 0.40 & 0.38 & 0.36 & 0.27 & 0.70 \\
\hline path & 0.02 & 0.20 & 0.39 & 0.31 & 0.39 & 0.40 & 0.22 \\
\hline & & \multicolumn{6}{|c|}{ Contemporaneous, $k=0$} \\
\hline target & 0.15 & 0.37 & 0.03 & 0.04 & 0.19 & 0.32 & 2.29 \\
\hline path & 0.04 & 0.06 & 0.37 & 0.35 & 0.28 & 0.19 & 0.57 \\
\hline
\end{tabular}

Table 7: Monetary policy surprises and information gaps. Information gaps are derived by taking the difference between the SFP and the ECB current or next year forecasts of real GDP and HICP.

The problem is that it is not easy to measure information sets. Campbell et al. (2017) use the difference between the Blue Chip forecasts and the Greenbook forecasts as an observable proxy for information asymmetry. They interpret this difference as the amount of Delphic forward guidance contained in the monetary policy announcements. We follow the Campbell et al. (2017) and construct an observable proxy for the euro area. We consider inflation and real GDP forecasts obtained from the the Survey of Professional Forecasters as a measure of private sector forecasts and from the Eurosystem staff projections for the euro area as a measure of central bank forecasts. ${ }^{11}$ Tables 11 and 12 report the available figures at quarterly frequency. Unfortunately, there is a delay in the timing of the publication of the SPF forecasts and the Eurosystem staff macroeconomic projections; the latter are published on the day of the press conference and the former between three to four weeks before. This generates a discrepancy of information set that, we believe, is mostly due to the timing of the information flow, rather than to different expectations about the current and future states of the economy.

For what it's worth, we define the difference between the Eurosystem and SPF forecasts for the current year and the next year as a measures of information discrepancy. We have in total four times series. We then regress the target and path factors on these gaps, contemporaneously and lagged

$$
\begin{aligned}
\eta_{t}^{j}= & \beta_{0}+\beta_{1}\left(H I C P_{t-k}^{S P F}-H I C P_{t-k}^{E C B}\right)+\beta_{2}\left(H I C P(+1)_{t-k}^{S P F}-H I C P(+1)_{t-k}^{E C B}\right) \\
& +\beta_{3}\left(G D P_{t-k}^{S P F}-G D P_{t-k}^{E C B}\right)+\beta_{4}\left(G D P(+1)_{t-k}^{S P F}-G D P(+1)_{t-k}^{E C B}\right)+v_{t}
\end{aligned}
$$

for $j=t, p$ and $k=0,1$ and where $(+1)()$ indicates the next (current) year forecasts. We report the results in Table 7 . The regression results are poor. The $R^{2}$ results are low, and either singularly or jointly we fail to reject the singularity of coefficients. And even for $k=0$,

\footnotetext{
${ }^{11}$ Tables can be downloaded from the ECB webpage. See https://www.ecb.europa.eu/mopo/strategy/ecana/html/table.en.html and http://www.ecb.europa.eu/stats/prices/indic/forecast/html/table_hist_hicp.en.html
} 
the path factor is not explained by the discrepancy between central bank and private sector forecasts.

Miranda-Agrippino and Ricco (2017) propose to remove the component of the interest rate variations predictable by the central bank forecasts and forecast revisions and use the residual as a proxy for the monetary policy shock. We tried to construct the MirandaAgrippino and Ricco (2017) informationally robust instrument for the euro area using the Eurosystem staff macroeconomic projections and forecast revisions. Along the lines of their analysis of the US monetary policy, we specified the following regression

$$
f_{t}^{j}=\alpha_{0}+\beta(L) f_{t-1}^{j}+\gamma^{\prime} E C B_{t}^{p r o j}+\theta^{\prime} \Delta^{q} E C B_{t}^{p r o j}+e_{t}
$$

where $j=$ Target, Path,Odyssean,Delphic and $E C B_{t}^{\text {proj }}=\left[\pi_{\text {current } Y}, \pi_{\text {next } Y}, G D P_{\text {current } Y}, G D P_{\text {next } Y}\right]^{\prime}$ contains projections for output growth and inflation for current and next year; and $\Delta^{q} E C B_{t}^{\text {proj }}$ is their revision relative to the previous quarter. The residual of this regression is the informationally robust monetary policy instrument.

The major complication with this approach is the sample size reduction. The Eurosystem projections are released quarterly and the monetary policy surprises are monthly. We considered the monetary policy surprises that are paired with the staff macro projections. This reduces our sample size from 135 to 46 for Delphic and Odyssean factors and from 169 to 55 for target and path factors. Notice that since we are removing two-thirds of the observations, the new series $f_{t}^{j}$ might not be centered at zero and with zero autocorrelation.

We run the full regression specification (see table 9) and two separate regressions with either the Eurosystem projections or forecast revisions (see table 8). The OLS estimates, statistical significance, Adjusted $R^{2}$ results and F test results are reported. Standard errors are computed with robust covariance estimates for ordinary least squares. In the stripped down regressions (table 8), monetary policy target surprises are explained by the Eurosystem projections of inflation for the current year and next year; the sign for the next year is puzzling. Nothing else is statistically significant (except for constants), and the measures of fit are low. In the full specification, results are similar for the monetary policy target surprises. For the path factor, Eurosystem forecasts and revisions are statistically significant at the $10 \%$ confidence level. However, the fit of the specification is worse than the one obtained with the stripped down regressions; the Adjusted $R^{2}$ is -0.08 in the full specification regression and 0.01 or -0.03 in the stripped down regressions.

Our takeaway is consistent with the results on the predictability of monetary policy surprises. We found that the target responds to the factor 5 in table 3 . And factor 5 is associated with measures of inflation. Therefore, it is not surprising to see that the target responds to the Eurosystem forecasts of inflation. In any case, we do not think that there is enough evidence in order to conclude that the path, the Odyssean, or the Delphic factor responds to Eurosystem forecasts and forecast revisions. 


\begin{tabular}{c|cccc} 
& Target & Path & Delphic & Odyssean \\
\hline & & & & \\
const & 0.02 & 0.00 & 0.04 & 0.02 \\
$\pi_{\text {current } Y}$ & $0.01^{* *}$ & -0.02 & 0.01 & -0.00 \\
$\pi_{\text {next } Y}$ & $-0.02^{* *}$ & 0.04 & -0.01 & -0.01 \\
$G D P_{\text {current } Y}$ & 0.00 & 0.00 & 0.01 & 0.00 \\
$G D P_{\text {next } Y}$ & -0.00 & -0.02 & -0.01 & 0.00 \\
Adj R2 & 0.06 & -0.03 & -0.04 & -0.07 \\
F test & 1.91 & 0.55 & 0.59 & 0.31 \\
& & & & \\
\hline & & & & \\
const & 0.00 & $0.02^{*}$ & $0.01^{* *}$ & 0.01 \\
$\Delta \pi_{\text {current } Y}$ & 0.01 & 0.03 & 0.01 & 0.00 \\
$\Delta \pi_{\text {next } Y}$ & -0.02 & -0.01 & -0.02 & -0.00 \\
$\Delta G D P_{\text {current } Y}$ & -0.00 & -0.01 & 0.00 & -0.00 \\
$\Delta G D P_{\text {next } Y}$ & 0.00 & 0.01 & -0.01 & 0.00 \\
F test & 0.48 & 0.36 & 0.63 & 0.09 \\
Adj R2 & -0.04 & -0.05 & -0.03 & -0.09 \\
& & & & \\
Sample size & 56 & 56 & 46 & 46 \\
& & & & \\
\hline & & & &
\end{tabular}

Table 8: Monetary policy surprises and Eurosystem staff projections and forecast revisions. OLS estimates and statistical significance, 1 (5 and 10)\% indicated with $* * *$ ( $* *$ and $*$ ) with robust SE. Top panel ECB forecasts, bottom panel ECB forecast revisions. 


\begin{tabular}{c|cccc} 
& Target & Path & Delphic & Odyssean \\
\hline const & -0.00 & 0.03 & 0.02 & -0.00 \\
AR1 & -0.09 & -0.04 & 0.11 & -0.15 \\
AR2 & 0.10 & -0.09 & -0.00 & -0.07 \\
AR3 & $-0.42^{* *}$ & -0.18 & -0.26 & -0.15 \\
$\pi_{\text {current } Y}$ & $0.04^{* * *}$ & $-0.05^{*}$ & 0.00 & 0.00 \\
$\pi_{\text {next } Y}$ & $-0.04^{* *}$ & $0.08^{*}$ & 0.01 & -0.01 \\
$G D P_{\text {current } Y}$ & -0.00 & 0.01 & 0.00 & -0.00 \\
$G D P_{\text {next } Y}$ & -0.00 & $-0.04^{*}$ & -0.02 & 0.01 \\
$\Delta \pi_{\text {current } Y}$ & -0.01 & $0.05^{*}$ & 0.01 & -0.00 \\
$\Delta \pi_{\text {next } Y}$ & 0.01 & -0.04 & -0.03 & 0.00 \\
$\Delta G D P_{\text {current } Y}$ & 0.00 & -0.02 & -0.00 & 0.00 \\
$\Delta G D P_{\text {next } Y}$ & 0.01 & 0.03 & 0.00 & -0.00 \\
Adj R2 & 0.24 & -0.08 & -0.10 & -0.31 \\
F test & 2.44 & 0.65 & 0.66 & 0.13 \\
Sample size & 51 & 51 & 41 & 41 \\
& & & &
\end{tabular}

Table 9: Monetary policy surprises and Eurosystem staff projections and revisions. The OLS estimates and statistical significance, $1(5$ and 10$) \%$ indicated with $* * *(* *$ and $*)$ with robust SE.

\section{A.4 TIME VARIATION OF THE RESPONSE OF ILS}

To gauge more evidence on the possible time variation in the impact of the target and path factors on inflation expectations, we conducted two complementary exercises where we do not arbitrarily select the subsamples. The first exercise is based on a rolling window regression and the second on a local kernel regression, which has the advantage of smoothing the abrupt time variation of the rolling window estimates. The local kernel regression is a form of rolling regression with a different data weighting scheme. More formally, for each $\tau=1, . ., T$, we minimize the following residual sum squares:

$$
\sum_{t=1}^{T} K_{f}\left(\frac{t-\tau}{h}\right)\left(I L S_{j, t}-\eta_{t}^{\prime} B_{\tau}\right),
$$

where $K_{f}($.$) is the Gaussian kernel function and h$ is the bandwidths, and where $\eta_{t}$ collects the path and target factors (and a constant). Data points far form $\tau$ will have small weights, yet are nonzero as in the rolling window. ${ }^{12}$ Figure 6 reports the rolling sample estimates of the impact of the target factor (left panels) and path factor (right panels) on market-based inflation expectations. In particular, the blue solid and dashed lines plot the OLS estimates of regressing the financial instrument on the target factor and the path factor along with the

\footnotetext{
${ }^{12}$ We use the optimal bandwidth as suggested by Bowman and Azzalini (1997). Since the weighting scheme is known, standard weighted least square methods can be used to estimate the parameters, $B_{\tau}$.
} 
$90 \%$ confidence bands in a 24-month window. The gray areas report the same information using a local linear kernel estimator. The impact of the target factor tends to be relatively stable over the rolling windows, fluctuating between negative or nonsignificant values. The impact of the path factor instead displays slowly moving time variation, switching from positive to negative values.

ECB Nominal effective exch. Rate

UK pound sterling/Euro, 2:15 pm (C.E.T.) 1

Japanese yen/Euro, 2:15 pm (C.E.T.) 1

US dollar/Euro, 2:15 pm (C.E.T.) 1

Total Turnover Index, Manifacturing 2

ECB Commodity Price index Euro denominated 2

Standardised unemployment, Rate, 1

Car registration, New passenger car; $\quad 2$

Total Turnover Index, Retail trade including fuel 2

New orders, total, MANUFACTURING, FOR NEW ORDERS 2

Industrial Production Index, Total Industry (excluding construction) 2

Industrial Production Index, Total Industry excluding construction and MIG Energy 2

Brent crude oil 1-month Forward 2

Equity index - Dow Jones Eurostoxx 50 index - Index 2

Rate - Eonia rate - Euro 1

Rate - 1-year Euribor (Euro interbank offered rate) - Euro 1

Rate - 3-month Euribor (Euro interbank offered rate) - Euro 1

Equity index - Standard and Poor 500 - Index 2

Exchange rate, ECB real effective exchange rate CPI deflated 2

Loans, total maturity, all currencies combined 2

Monetary aggregate M3, all currencies combined 2

HICP - Overall index - Index 2

HICP - All-items excluding energy and unprocessed food - Index 2

Standardised unemployment, Total (all ages), Male - Percentage 1

Consumer Survey - Consumer Confidence Indicator - Percentage 2

Economic Sentiment Indicator - Percentage 2

Industrial Production Index, Consumer goods industry - Index 2

Industrial Production Index, MIG Durable Consumer Goods Industry - Index 2

Industrial Production Index, MIG Energy - Index 2

Industrial Production Index, Total Industry - Index 2

Industrial Production Index, MIG Intermediate Goods Industry - Index 2

United States - CONSUMER PRICES, ALL ITEMS 2

United States - Employment 1

United States - 10-Year Treasury Constant Maturity Rate 1

United States - Manufacturing ISM Report on Business 2

United States - Real Retail and Food Services Sales 2

United States - Three months treasury bill 1

United States - Unemployment rate 1

Table 10: List of variables included in $X_{t}$ to test the predictability of monetary policy surprises. Transformations: $1=$ first difference, $2=$ growth rate 


\begin{tabular}{|c|c|c|c|c|}
\hline & \multicolumn{2}{|c|}{ HICP } & \multicolumn{2}{|c|}{ Real GDP } \\
\hline & Current $\mathrm{Y}$ & Next Y & Current Y & Next Y \\
\hline March 2002 & 1.8 & 1.6 & 1.0 & 2.5 \\
\hline June 2002 & 2.3 & 1.9 & 1.2 & 2.6 \\
\hline September 2002 & 2.2 & 1.8 & 0.8 & 2.1 \\
\hline December 2002 & 2.2 & 1.8 & 0.8 & 1.6 \\
\hline March 2003 & 2.0 & 1.5 & 1.0 & 2.0 \\
\hline June 2003 & 2.0 & 1.3 & 0.7 & 1.6 \\
\hline September 2003 & 2.1 & 1.5 & 0.4 & 1.5 \\
\hline December 2003 & 2.1 & 1.8 & 0.4 & 1.6 \\
\hline March 2004 & 1.7 & 1.5 & 1.5 & 2.4 \\
\hline June 2004 & 2.1 & 1.7 & 1.7 & 2.2 \\
\hline September 2004 & 0.2 & 1.3 & 1.6 & 1.7 \\
\hline December 2004 & 2.2 & 2.0 & 1.8 & 1.9 \\
\hline March 2005 & 1.9 & 1.6 & 1.6 & 2.1 \\
\hline June 2005 & 2.0 & 1.5 & 1.4 & 2.0 \\
\hline September 2005 & 2.2 & 1.9 & 1.3 & 1.8 \\
\hline December 2005 & 2.2 & 2.1 & 1.4 & 1.9 \\
\hline March 2006 & 2.2 & 2.2 & 2.1 & 2.0 \\
\hline June 2006 & 2.3 & 2.2 & 2.1 & 1.8 \\
\hline September 2006 & 2.4 & 2.4 & 2.5 & 2.1 \\
\hline December 2006 & 2.2 & 2.0 & 2.7 & 2.2 \\
\hline March 2007 & 1.8 & 2.0 & 2.5 & 2.4 \\
\hline June 2007 & 2.0 & 2.0 & 2.6 & 2.3 \\
\hline September 2007 & 2.0 & 2.0 & 2.5 & 2.3 \\
\hline December 2007 & 2.1 & 2.5 & 2.6 & 2.0 \\
\hline March 2008 & 2.9 & 2.1 & 1.7 & 1.8 \\
\hline June 2008 & 3.4 & 2.4 & 1.8 & 1.5 \\
\hline September 2008 & 3.5 & 2.6 & 1.4 & 1.2 \\
\hline December 2008 & 3.3 & 1.4 & 1.0 & -0.5 \\
\hline March 2009 & 0.4 & 1.0 & -2.7 & 0.0 \\
\hline June 2009 & 0.3 & 1.0 & -4.6 & -0.3 \\
\hline September 2009 & 0.4 & 1.2 & -4.1 & 0.2 \\
\hline December 2009 & 0.3 & 1.3 & -4.0 & 0.8 \\
\hline March 2010 & 1.2 & 1.5 & 0.8 & 1.5 \\
\hline June 2010 & 1.5 & 1.6 & 1.0 & 1.2 \\
\hline September 2010 & 1.6 & 1.7 & 1.6 & 1.4 \\
\hline December 2010 & 1.6 & 1.8 & 1.7 & 1.4 \\
\hline March 2011 & 2.3 & 1.7 & 1.7 & 1.8 \\
\hline June 2011 & 2.6 & 1.7 & 1.9 & 1.7 \\
\hline September 2011 & 2.6 & 1.7 & 1.6 & 1.3 \\
\hline December 2011 & 2.7 & 2.0 & 1.6 & 0.3 \\
\hline March 2012 & 2.4 & 1.6 & -0.1 & 1.1 \\
\hline June 2012 & 2.4 & 1.6 & -0.1 & 1.0 \\
\hline September 2012 & 2.5 & 1.9 & -0.4 & 0.5 \\
\hline December 2012 & 2.5 & 1.6 & -0.5 & -0.3 \\
\hline March 2013 & 1.6 & 1.3 & -0.5 & 1.0 \\
\hline June 2013 & 1.4 & 1.3 & -0.6 & 1.1 \\
\hline September 2013 & 1.5 & 1.3 & -0.4 & 1.0 \\
\hline December 2013 & 1.4 & 1.1 & -0.4 & 1.1 \\
\hline March 2014 & 1.0 & 1.3 & 1.2 & 1.5 \\
\hline June 2014 & 0.7 & 1.1 & 1.0 & 1.7 \\
\hline September 2014 & 0.6 & 1.1 & 0.9 & 1.6 \\
\hline December 2014 & 0.5 & 0.7 & 0.8 & 1.0 \\
\hline March 2015 & 0.0 & 1.5 & 1.5 & 1.9 \\
\hline June 2015 & 0.3 & 1.5 & 1.5 & 1.9 \\
\hline September 2015 & 0.1 & 1.1 & 1.4 & 1.7 \\
\hline December 2015 & 0.1 & 1.0 & 1.5 & 1.7 \\
\hline March 2016 & 0.1 & 1.3 & 1.4 & 1.7 \\
\hline June 2016 & 0.2 & 1.3 & 1.6 & 1.7 \\
\hline
\end{tabular}

Table 11: Eurosystem staff projections for the euro area, inflation and real GDP. 


\begin{tabular}{|c|c|c|c|c|}
\hline & \multicolumn{2}{|c|}{ HICP } & \multicolumn{2}{|c|}{ Real GDP } \\
\hline & Current Y & Next Y & Current Y & Next Y \\
\hline 2002 Q1 & 1.7 & 1.8 & 1.3 & 2.6 \\
\hline $2002 \mathrm{Q} 2$ & 2.1 & 1.9 & 1.4 & 2.7 \\
\hline 2002 Q3 & 2.1 & 1.8 & 1.2 & 2.5 \\
\hline $2002 \mathrm{Q} 4$ & 2.2 & 1.8 & 0.8 & 1.8 \\
\hline 2003 Q1 & 1.8 & 1.8 & 1.4 & 2.3 \\
\hline 2003 Q2 & 2.0 & 1.7 & 1.0 & 2.1 \\
\hline 2003 Q3 & 1.9 & 1.5 & 0.7 & 1.7 \\
\hline $2003 \mathrm{Q} 4$ & 2.0 & 1.6 & 0.5 & 1.7 \\
\hline 2004 Q1 & 1.8 & 1.7 & 1.8 & 2.2 \\
\hline 2004 Q2 & 1.8 & 1.8 & 1.6 & 2.1 \\
\hline 2004 Q3 & 2.1 & 1.9 & 1.8 & 2.1 \\
\hline 2004 Q4 & 2.1 & 1.9 & 1.9 & 2.0 \\
\hline 2005 Q1 & 1.9 & 1.8 & 1.8 & 2.1 \\
\hline $2005 \mathrm{Q} 2$ & 1.9 & 1.8 & 1.6 & 2.0 \\
\hline 2005 Q3 & 2.1 & 1.8 & 1.4 & 1.8 \\
\hline $2005 \mathrm{Q} 4$ & 2.2 & 2.0 & 1.3 & 1.7 \\
\hline 2006 Q1 & 2.0 & 2.0 & 2.0 & 1.9 \\
\hline 2006 Q2 & 2.1 & 2.1 & 2.1 & 1.9 \\
\hline 2006 Q3 & 2.3 & 2.1 & 2.2 & 1.8 \\
\hline $2006 \mathrm{Q} 4$ & 2.2 & 2.1 & 2.6 & 2.0 \\
\hline 2007 Q1 & 2.0 & 1.9 & 2.1 & 2.1 \\
\hline 2007 Q2 & 1.9 & 1.9 & 2.5 & 2.3 \\
\hline 2007 Q3 & 2.0 & 2.0 & 2.7 & 2.3 \\
\hline $2007 \mathrm{Q} 4$ & 2.0 & 2.0 & 2.6 & 2.1 \\
\hline 2008 Q1 & 2.5 & 2.0 & 1.8 & 2.0 \\
\hline 2008 Q2 & 3.0 & 2.2 & 1.6 & 1.6 \\
\hline 2008 Q3 & 3.6 & 2.6 & 1.6 & 1.3 \\
\hline $2008 \mathrm{Q} 4$ & 3.4 & 2.2 & 1.2 & 0.3 \\
\hline 2009 Q1 & 0.9 & 1.6 & -1.0 & 0.6 \\
\hline 2009 Q2 & 0.5 & 1.3 & -3.0 & 0.2 \\
\hline 2009 Q3 & 0.4 & 1.1 & -4.0 & 0.3 \\
\hline 2009 Q4 & 0.3 & 1.2 & -3.0 & 1.0 \\
\hline 2010 Q1 & 1.3 & 1.5 & 1.2 & 1.6 \\
\hline 2010 Q2 & 1.4 & 1.5 & 1.1 & 1.5 \\
\hline 2010 Q3 & 1.4 & 1.5 & 1.1 & 1.4 \\
\hline 2010 Q4 & 1.5 & 1.5 & 1.6 & 1.5 \\
\hline 2011 Q1 & 1.9 & 1.8 & 1.6 & 1.7 \\
\hline $2011 \mathrm{Q} 2$ & 2.5 & 1.9 & 1.7 & 1.7 \\
\hline 2011 Q3 & 2.6 & 2.0 & 1.9 & 1.6 \\
\hline 2011 Q4 & 2.6 & 1.8 & 1.6 & 0.8 \\
\hline 2012 Q1 & 1.9 & 1.7 & -0.0 & 1.1 \\
\hline 2012 Q2 & 2.3 & 1.8 & -0.0 & 1.0 \\
\hline 2012 Q3 & 2.3 & 1.7 & -0.0 & 0.6 \\
\hline $2012 \mathrm{Q} 4$ & 2.5 & 1.9 & -0.0 & 0.3 \\
\hline 2013 Q1 & 1.8 & 1.8 & -0.0 & 1.1 \\
\hline 2013 Q2 & 1.7 & 1.6 & -0.0 & 1.0 \\
\hline 2013 Q3 & 1.5 & 1.5 & -0.0 & 0.9 \\
\hline 2013 Q4 & 1.4 & 1.5 & -0.0 & 1.0 \\
\hline 2014 Q1 & 1.1 & 1.4 & 1.0 & 1.5 \\
\hline 2014 Q2 & 0.9 & 1.3 & 1.1 & 1.5 \\
\hline 2014 Q3 & 0.7 & 1.2 & 1.0 & 1.5 \\
\hline 2014 Q4 & 0.5 & 1.0 & 0.8 & 1.2 \\
\hline 2015 Q1 & 0.3 & 1.1 & 1.1 & 1.5 \\
\hline 2015 Q2 & 0.1 & 1.2 & 1.4 & 1.7 \\
\hline 2015 Q3 & 0.2 & 1.3 & 1.4 & 1.8 \\
\hline $2015 \mathrm{Q} 4$ & 0.1 & 1.0 & 1.5 & 1.7 \\
\hline 2016 Q1 & 0.7 & 1.4 & 1.7 & 1.8 \\
\hline 2016 Q2 & 0.3 & 1.3 & 1.5 & 1.6 \\
\hline
\end{tabular}

Table 12: SPF projections for the euro area, inflation and real GDP. 


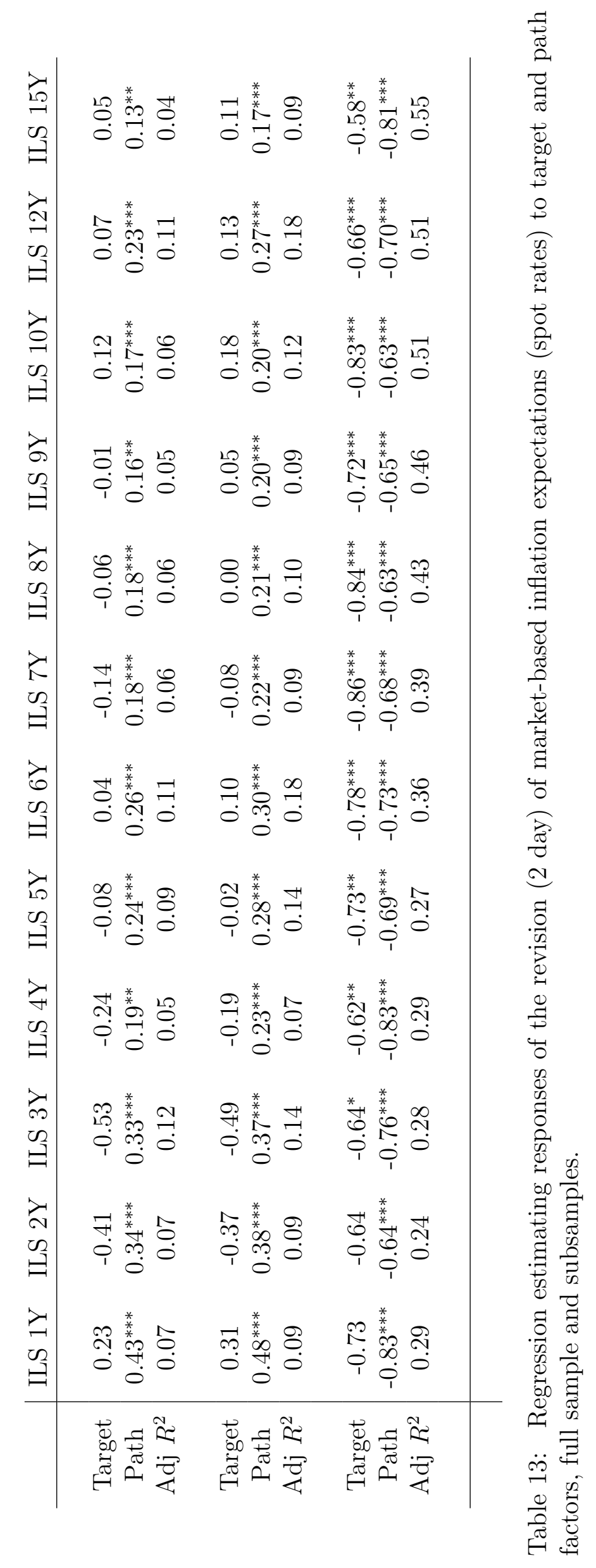




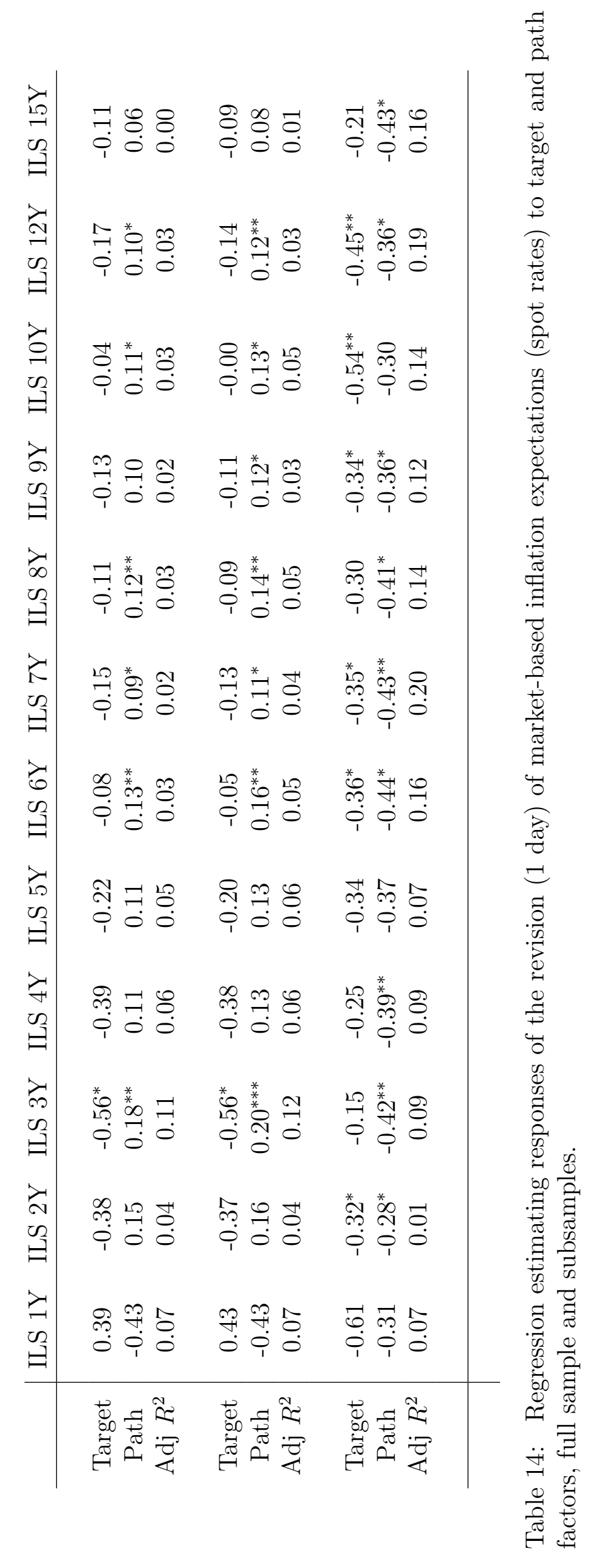




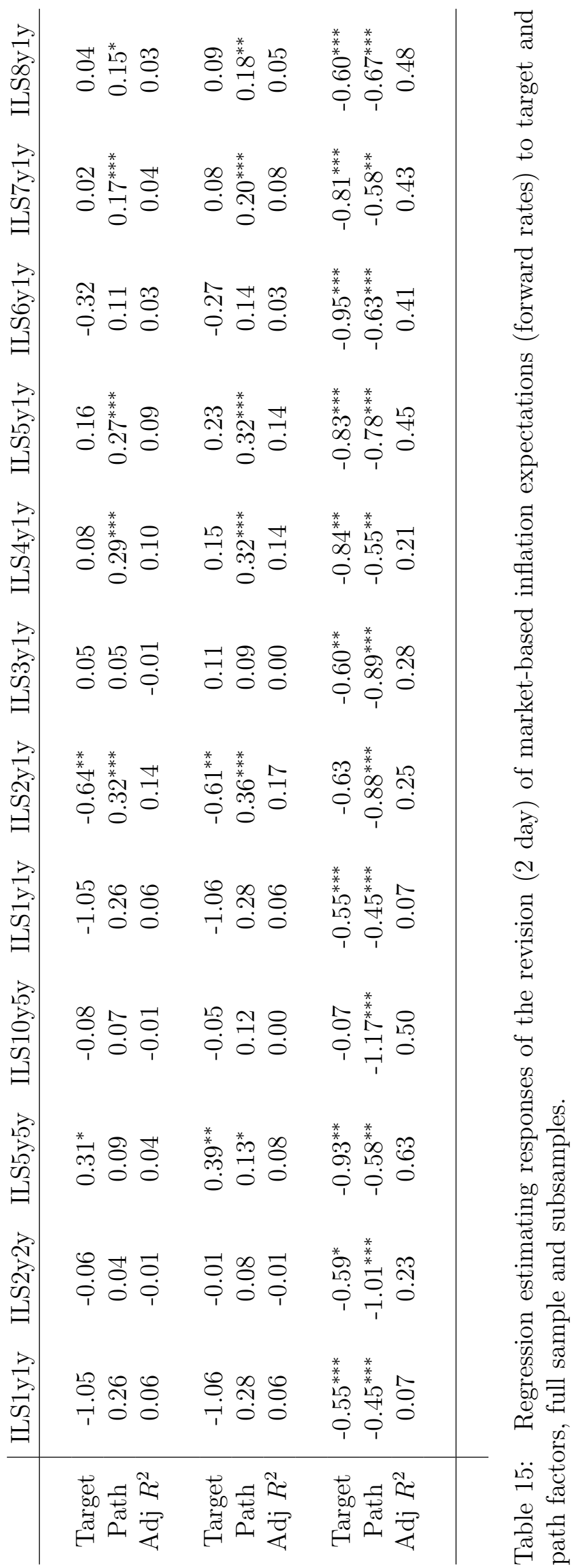




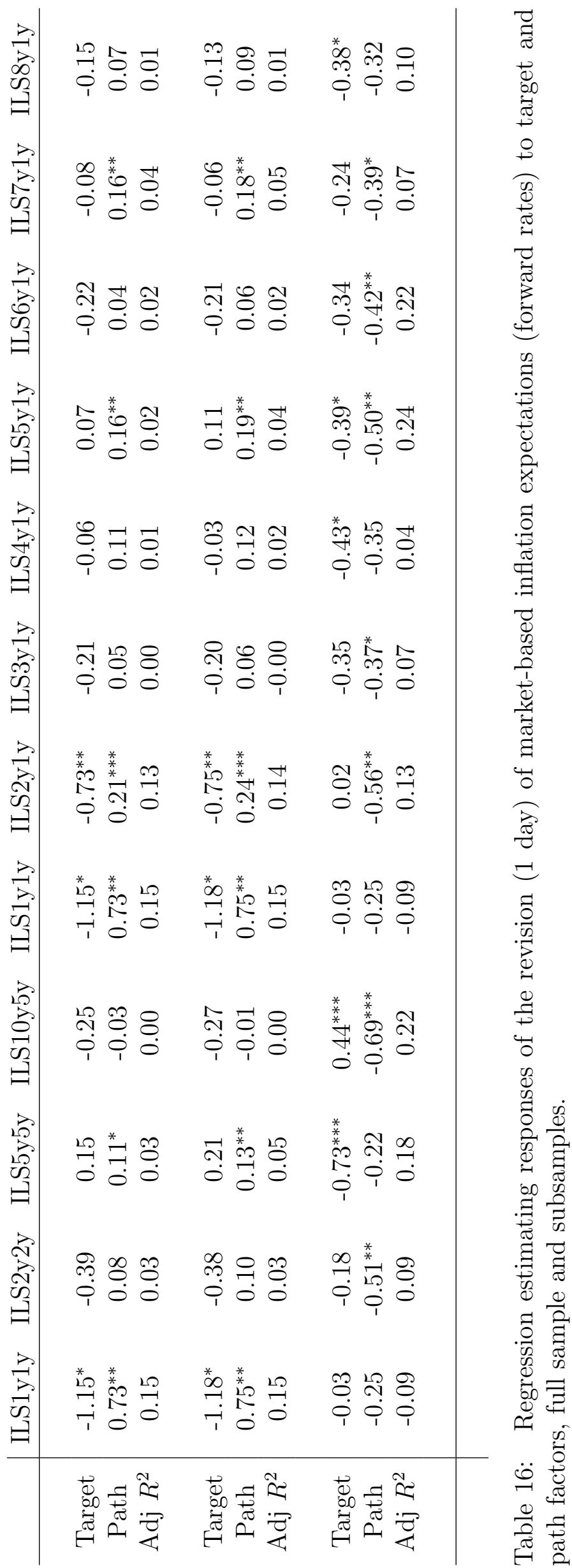




\begin{tabular}{|c|c|c|}
\hline & $R^{2}$ & OLS Coeff \\
\hline CORE & 0.29 & 1.82 \\
\hline HICP & 0.27 & 1.99 \\
\hline TURNOVERRET & 0.07 & 0.04 \\
\hline ESI & 0.06 & -0.22 \\
\hline DJ50 & 0.05 & -0.07 \\
\hline SP500 & 0.05 & -0.09 \\
\hline IPIEN & 0.05 & -0.05 \\
\hline CCI & 0.04 & $-0.21^{* * *}$ \\
\hline NAPM & 0.04 & -0.08 \\
\hline UNRATEPER & 0.02 & $0.17^{*}$ \\
\hline EONIA & 0.01 & $1.24^{*}$ \\
\hline IPINOCOSTR & 0.01 & -0.18 \\
\hline M3 & 0.01 & $-0.38^{* * *}$ \\
\hline IPIINTER & 0.01 & -0.01 \\
\hline IPINOCOSTREN & 0.01 & -0.14 \\
\hline TURNOVERMAN & 0.01 & 0.02 \\
\hline UNRATE & 0.01 & $1.84^{* * *}$ \\
\hline UKEUROSPOT & 0.01 & 8.27 \\
\hline GS10 & 0.01 & -0.68 \\
\hline PCOMM & 0.01 & $-0.04^{*}$ \\
\hline 1YEURIBOR & 0.01 & $-0.76^{* * *}$ \\
\hline UNRATEUS & 0.01 & $0.71^{* * *}$ \\
\hline BRENT & 0.01 & 0.01 \\
\hline CE16OV & 0.01 & $-0.47^{* * *}$ \\
\hline TB3MS & 0.00 & $-0.55^{* * *}$ \\
\hline 3MEURIBOR & 0.00 & -0.51 \\
\hline CPIUS & 0.00 & 0.20 \\
\hline NEWORDER & 0.00 & $-0.03^{* * *}$ \\
\hline CARREG & 0.00 & -0.00 \\
\hline DOLEUROSPOT & 0.00 & $-1.53^{*}$ \\
\hline REXRATE & 0.00 & -0.03 \\
\hline YENEUROSPOT & 0.00 & 0.01 \\
\hline RRSFS & 0.00 & 0.04 \\
\hline IPICONS & 0.00 & $-0.00^{* *}$ \\
\hline IPITOT & 0.00 & 0.00 \\
\hline LOANS & 0.00 & -0.03 \\
\hline IPIDUR & 0.00 & 0.00 \\
\hline
\end{tabular}

Table 17: Regression Estimating $f_{5}$ on each observable variables in the factor model, i.e. $f_{5, t}=$ $\alpha_{0}+\alpha_{0} X_{j, t}+e_{t}$. OLS estimates and statistical significance, 1(5 and 10) \% indicated with $* * *$ $(* *$ and $*)$ with robust $\mathrm{SE}$. 


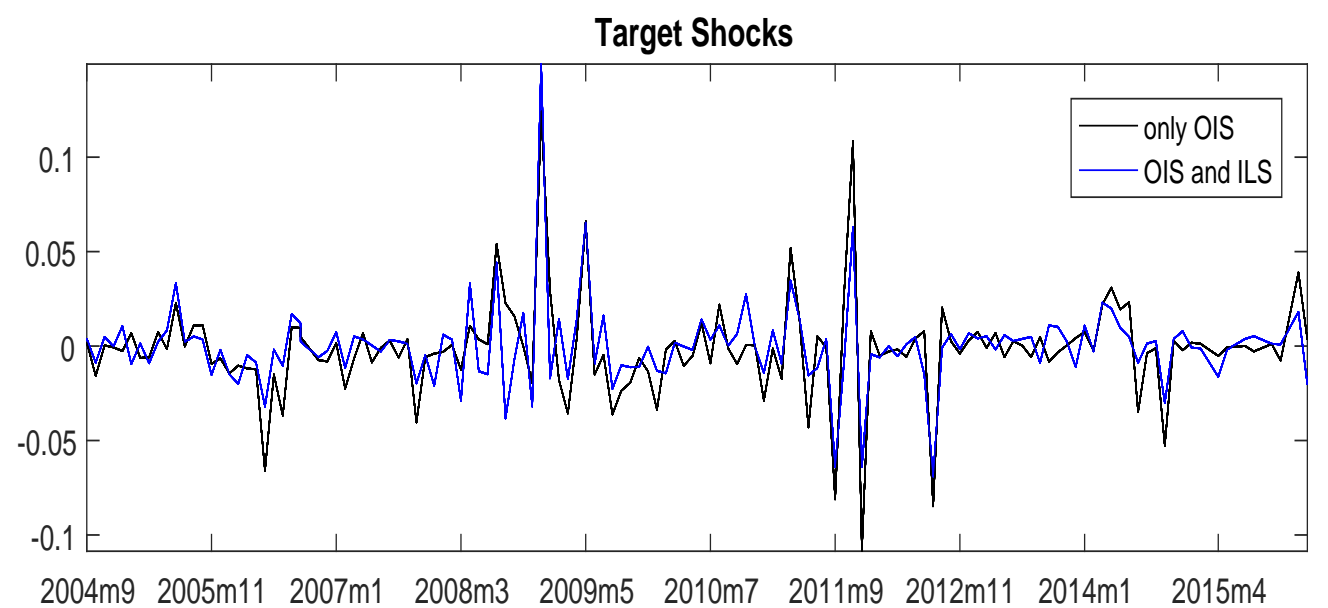

FG Path and Delphic Shocks

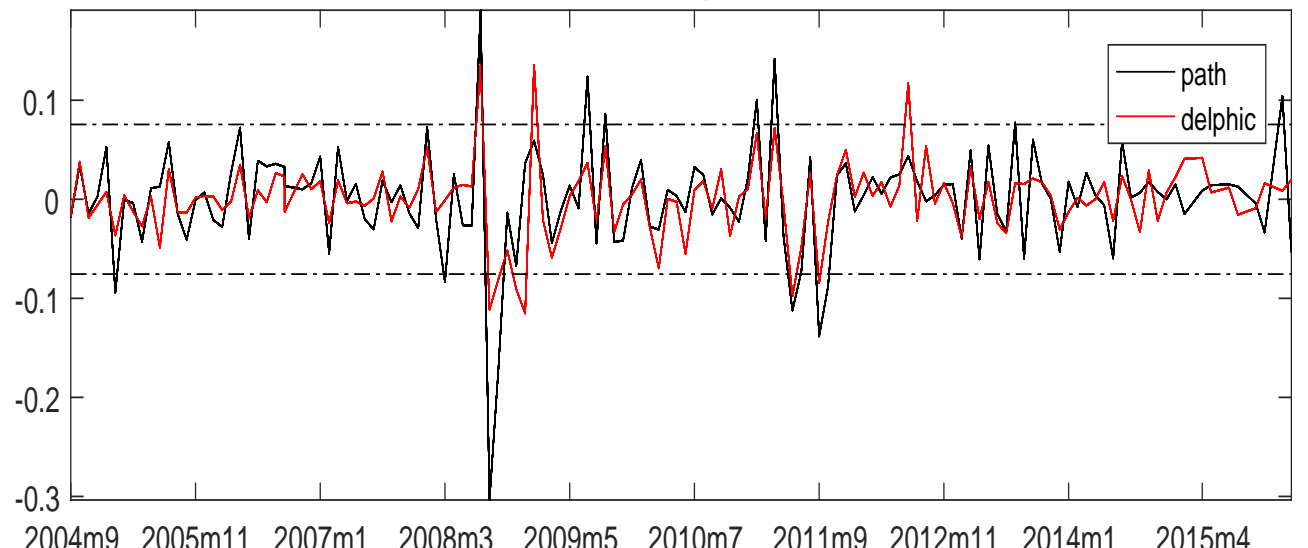

FG Odyssean Shocks

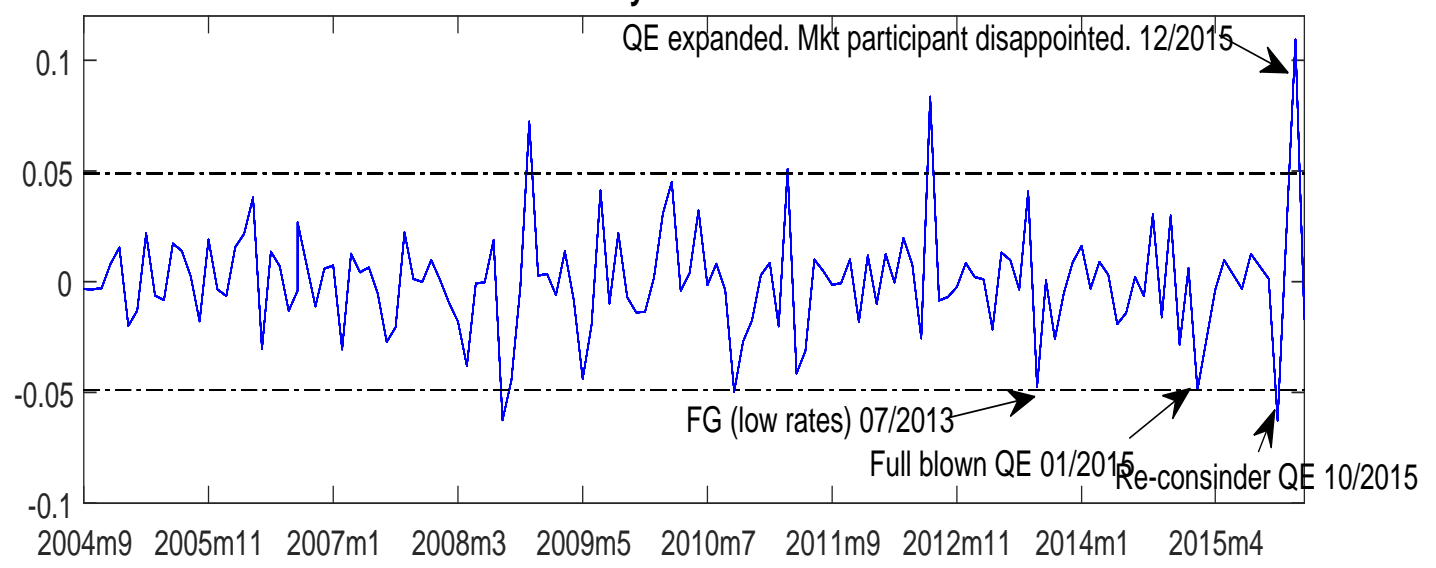

Figure 2: Target, path, and Delphic and Odyssean Forward Guidance (FG) shocks in percentage units. 

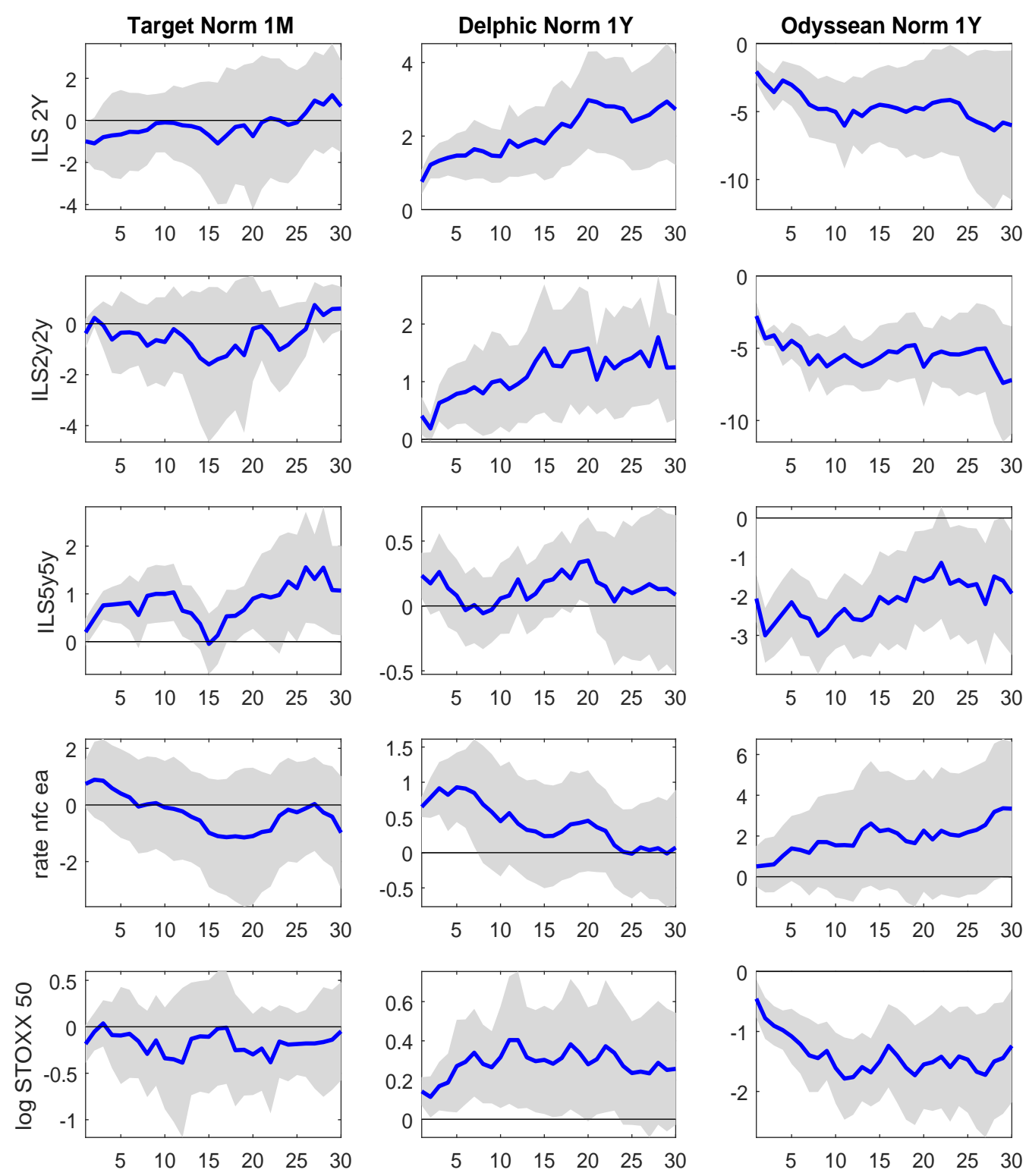

Figure 3: Persistence of monetary policy surprises. Impact of monetary policy surprises on two years, the two years in two years and the five years in five years ILS; the non-financial corporation borrowing rates; and the (log of) stock market prices $x$ days after the monetary policy announcement. 


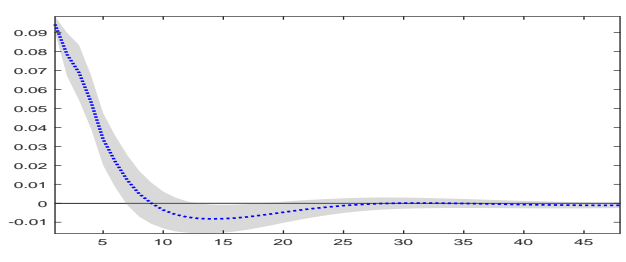

(a) Path to rates slope

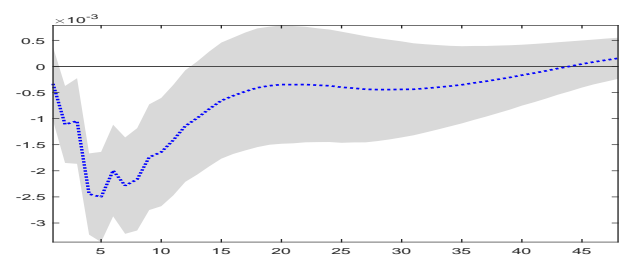

(c) Path to IP

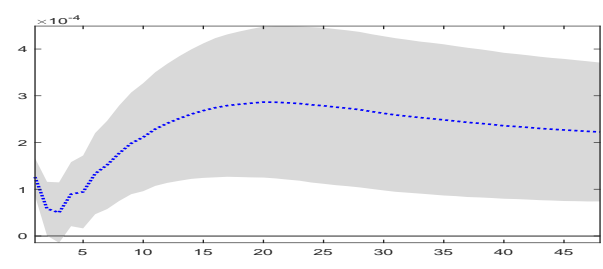

(e) Path to CORE

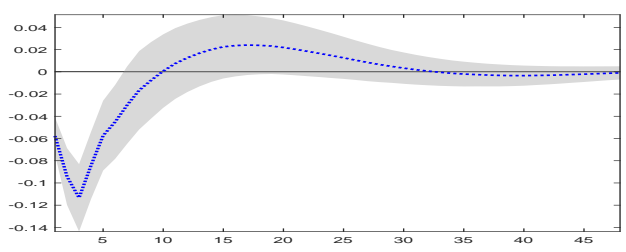

(g) Path to Credit Spread

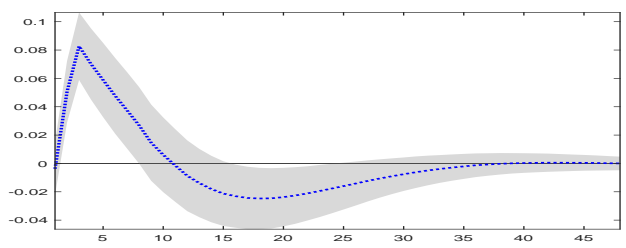

(i) Path to expected output growth

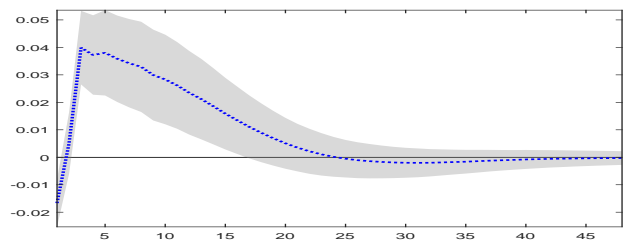

(k) Path to expected inflation

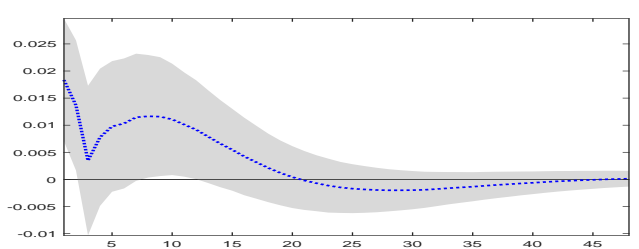

(b) Odyssean to rates slope

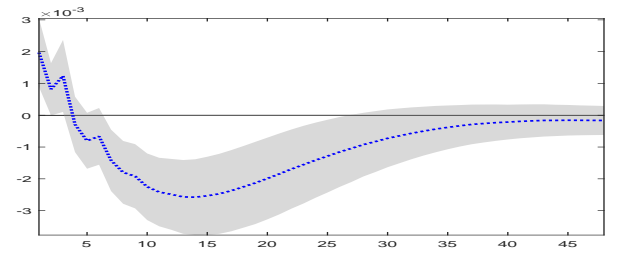

(d) Odyssean to IP

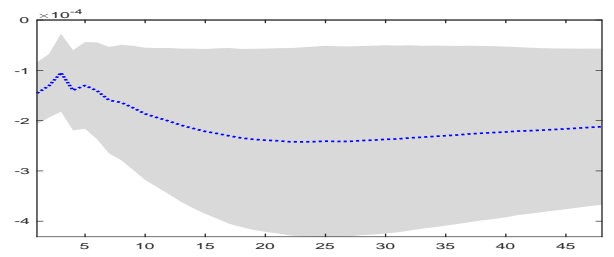

(f) Odyssean to CORE

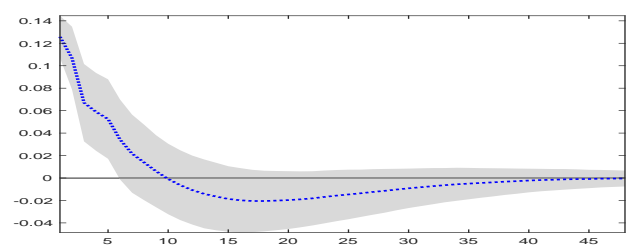

(h) Odyssean to Credit Spread

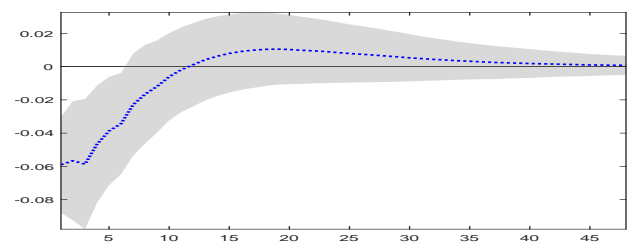

(j) Odyssean to expected output growth

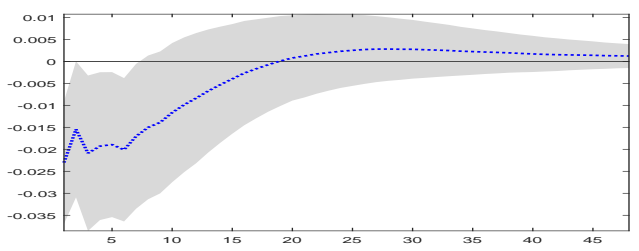

(l) Odyssean to expected inflation

Figure 4: Impulse responses of expectations, prices and output to the Odyssean monetary policy announcement and to a generic monetary policy announcement. The gray bands $68 \%$ confidence sets. 


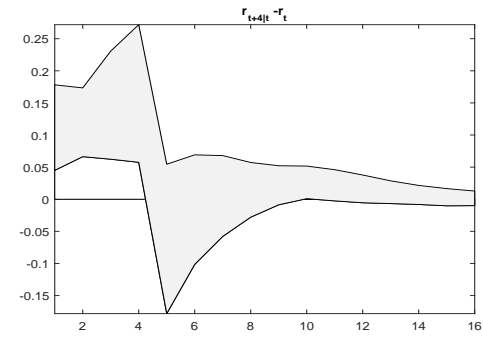

(a) Slope, $E_{t} r_{t+4}-r_{t}$

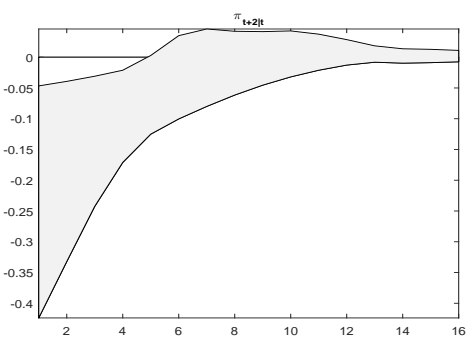

(c) $E_{t} \pi_{t+2}$



(b) $E_{t} \pi_{t+1}$



(d) $E_{t} \pi_{t+4}$

Figure 5: Responses to an announcement of a 5 basis points increase in interest rate (tightening) in one year's time. Gray areas contain all the possible impulse response functions (IRFs) drawing independently from the parameters priors. 


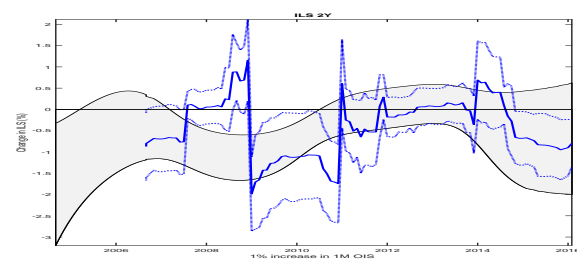

(a) Target on 2Y ILS

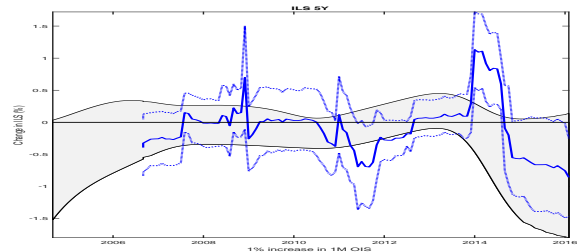

(c) Target on 5Y ILS

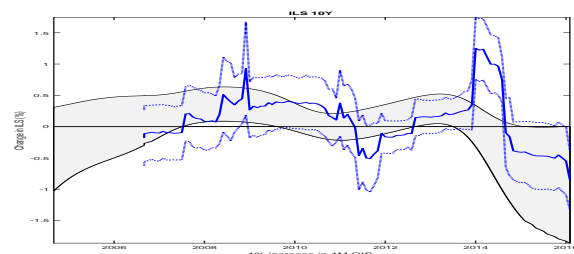

(e) Target on 10Y ILS

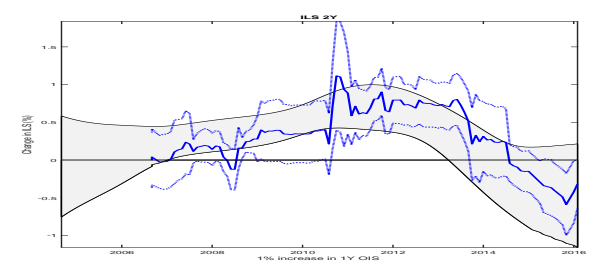

(b) Path on 2Y ILS

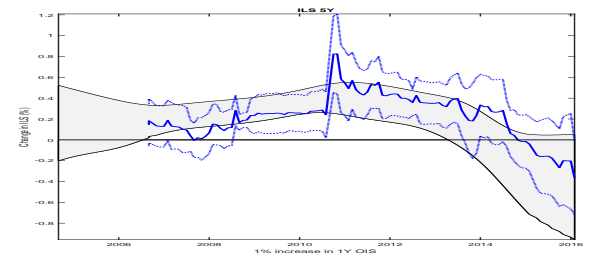

(d) Path on 5Y ILS

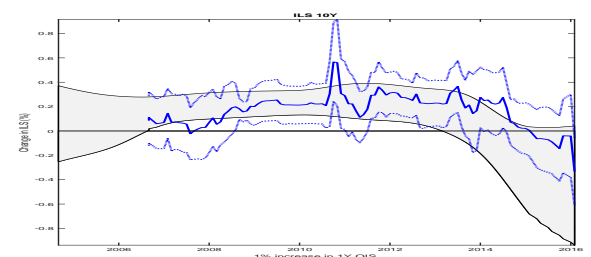

(f) Path on 10Y ILS

Figure 6: Impact of the path factor on the ILS over rolling windows or with a local kernel estimator 

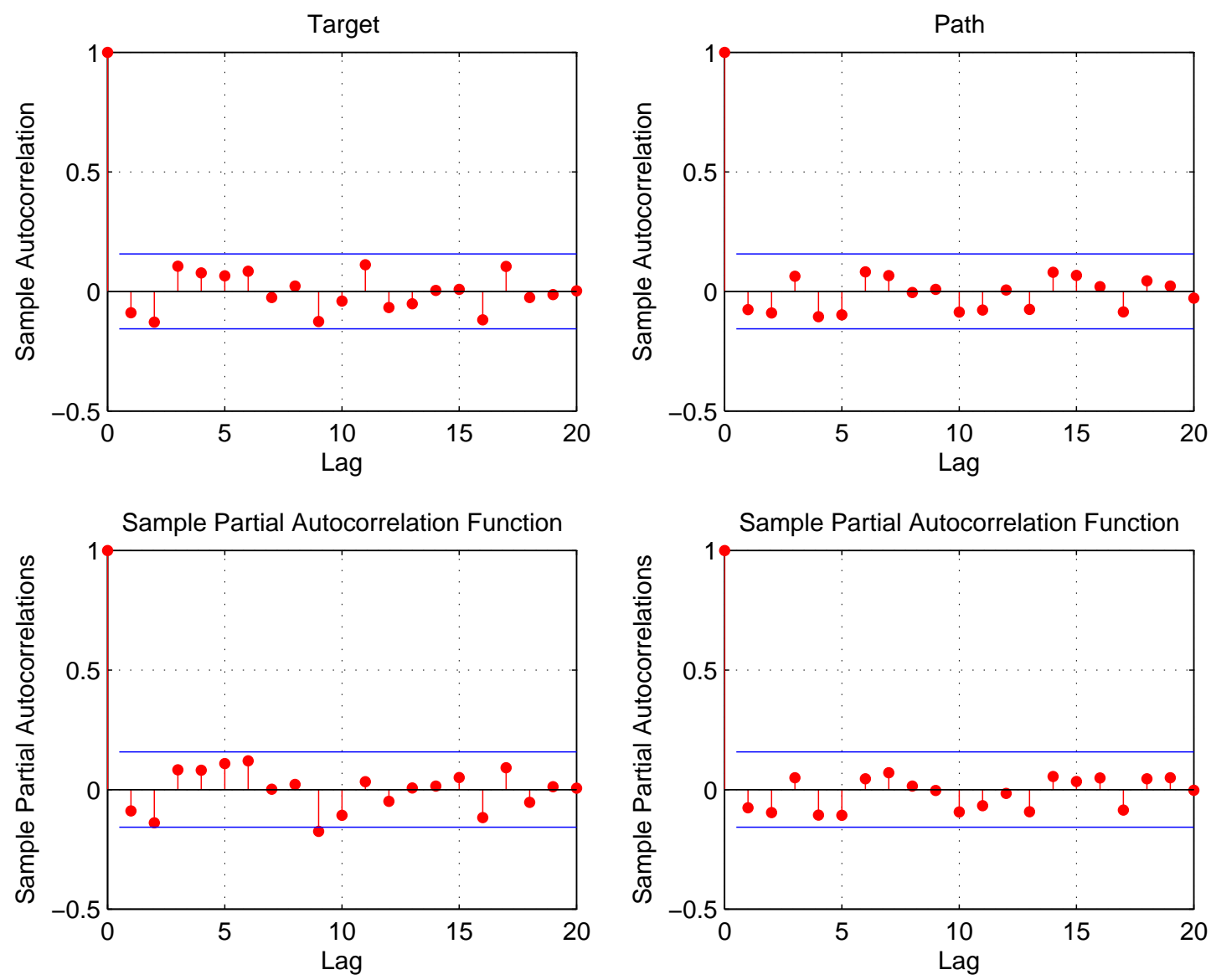

Figure 7: Autocorrelation and Partial Autocorrelation function for the path and the target factor. Blue bands indicate statistical significance.

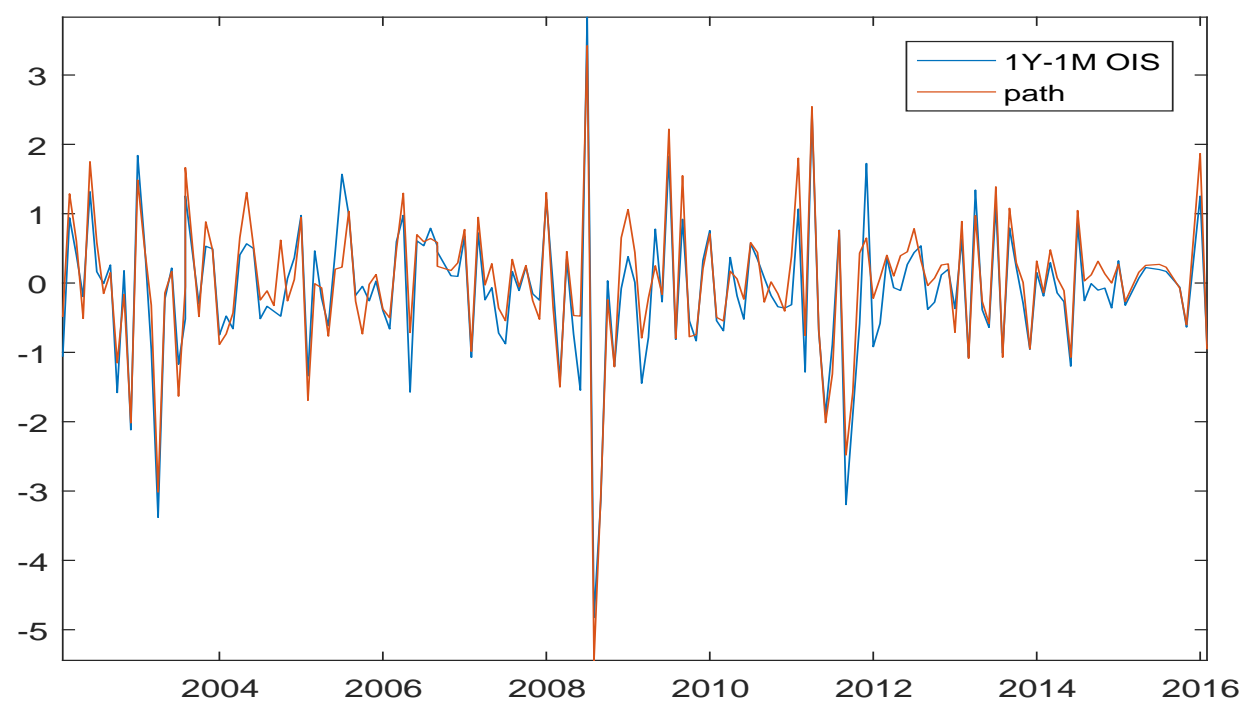

Figure 8: Plot of the path factor and the slope of (1y-1m) OIS swaps 

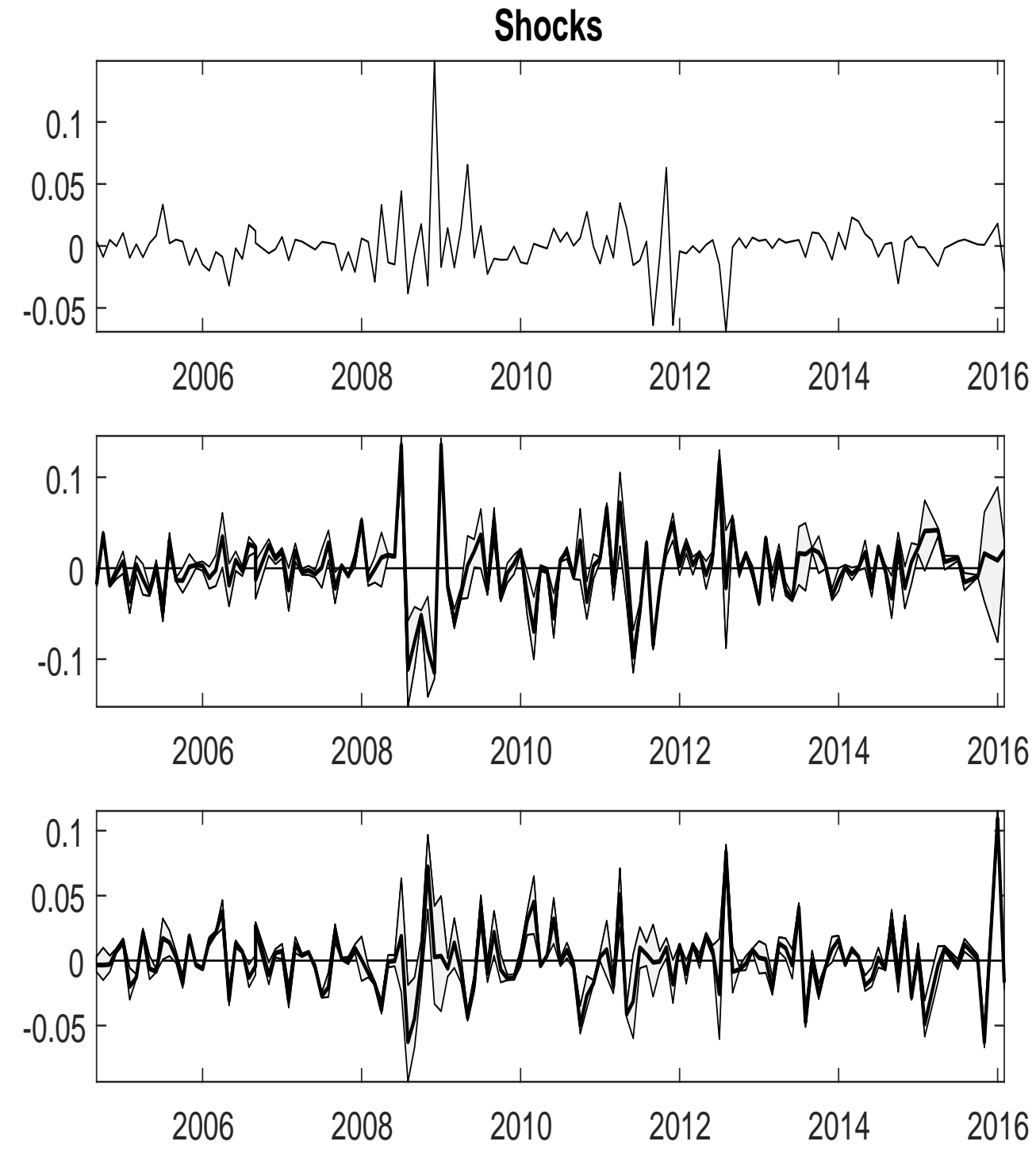

Figure 9: Plot of the target, Delphic and Odyssean factors with the set identification bands. 